\title{
Processamento da dor em indivíduos com lombalgia mecânica comum crônica com e sem afastamento do trabalho: um estudo de ressonância magnética funcional
}

Tese apresentada à Faculdade de Medicina da

Universidade de São Paulo para obtenção do título de Doutora em Ciências

Programa de Ciências Médicas

Área de Concentração: Educação e Saúde Orientador: Prof. Dr. Eduardo Ferreira Borba 
Dados Internacionais de Catalogação na Publicação (CIP)

Preparada pela Biblioteca da

Faculdade de Medicina da Universidade de São Paulo

Creprodução autorizada pelo

Feitosa, Aloma da Silva Alvares

Processamento da dor em indivíduos com lombalgia mecânica comum crônica com e sem afastamento do trabalho: um estudo de ressonância magnética funcional / Aloma da Silva Alvares Feitosa -- São Paulo, 2017.

Tese(doutorado)--Faculdade de Medicina da Universidade de São Paulo. Programa de Ciências Médicas. Área de concentração: Educação e Saúde.

Orientador: Eduardo Ferreira Borba Neto.

Descritores: 1. Lombalgia mecânica comum crônica 2. Licença médica 3. Neuroimagem funcional 4. Resposta hemodinâmica 5.Plasticidade neuronal 6.Percepção da dor

USP/FM/DBD-320/17 
"Se eu pudesse eu pegava a dor

Colocava dentro de um envelope e devolvería ao remetente" 


\section{Dedícatóría}

Dedico esta obra a todas as pessoas que participaram direita ou indiretamente da realização deste trabalho.

E a minha familia que sempre estive ao meu lado! 


\section{Agradecimentos}

Neste momento de fechamento de mais um ciclo da minha vida, gostaria muito de agradecer:

\section{À Deus por essa oportunidade!}

Aos meus pais, Aparecido Álvares e Raquel José Álvares, pela vida, por toda a proteção e cuidado ao longo de minha vida.

Ao meu marido, Altair Feitosa, muito obrigada pelo carinho, paciência e por sua capacidade de me trazer paz nos momentos difíceis.

Ao meu filho, Marcus Vinicius pelo carinho e compreensão.

À Faculdade de Medicina da Universidade de São Paulo pelo que representa para a ciência.

Ao departamento de reumatologia do Hospital da Clinicas de São Paulo, por todo o apoio para a realização deste trabalho e o incentivo financeiro.

Ao Dr. Eduardo Borba, que me aceitou como orientanda e me auxiliou nos momentos que precisei.

Ao Dr. Ari Stiel Radu Halpern, por todos os ensinamentos, pela oportunidade de desenvolver esse trabalho, por todo tempo dedicado, pelo seu apoio, confiança e incentivo. Muito obrigada!

Ao Dr. Edson Amaro, por todo o conhecimento compartilhado.

Ao programa de pesquisa do Instituto do Cérebro do Hospital Albert Einstein por todo o suporte na coleta de dados, ao departamento de fisioterapia do Hospital Albert Einstein, pelo auxilio na coleta dos voluntários e ao 
departamento de estatística do Hospital Albert Einstein, por todas as análises realizadas.

À Liana Guerra, biomédica do Hospital Albert Einstein, que além de participar de toda a coleta e análise de dados, foi fundamental para 0 entendimento de todos os termos técnicos relacionados com a ressonância funcional.

Às enfermeiras do Instituto do Cérebro, Karina e Alda por todo a acolhida com os voluntários.

Aos voluntários que participaram deste estudo.

À Sra. Bete responsável pela divulgação da pesquisa, no Hospital das Clínicas.

Ao meu paciente Dante Silvestre, pelas correções ortográficas.

Aos meus amigos pelo incentivo e apoio constantes.

À Coordenação de Aperfeiçoamento de Pessoal de Nível Superior (CAPES) e ao Instituto de pesquisa do Hospital Albert Einstein, pelo auxílio financeiro fornecido para o desenvolvimento desta pesquisa. 
Esta tese está de acordo com as seguintes normas, em vigor no momento desta publicação:

Referências: adaptado de International Committee of Medical Journais Editors (Vancouver).

Universidade de São Paulo. Faculdade de Medicina. Divisão de Biblioteca e Documentação. Guia de apresentação de dissertações, teses e monografias. Elaborado por Anneliese Carneiro da Cunha, Maria Julia de A. L Freddi, Maria F. Crestana, Marinalva de Souza Aragão, Suely Campos Cardoso, Valéria Vilhena. 3ํㅗㄹ ed. São Paulo: Divisão de Biblioteca e Documentação; 2011.

Abreviaturas dos títulos dos periódicos de acordo com Listo f Journals Indexed in Index Medicus. 


\section{Sumário}

Lista de abreviaturas

Lista de figuras

Lista de tabelas

Resumo

Abstract

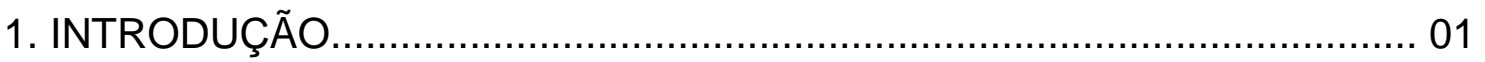

Hipótese do estudo: ........................................................... 07

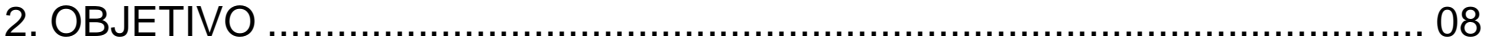

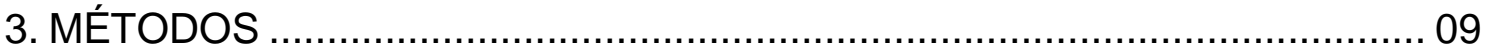

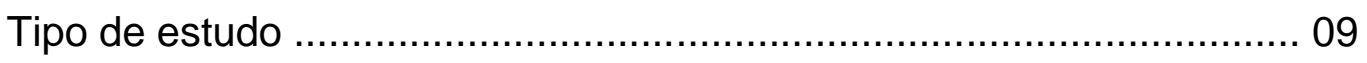

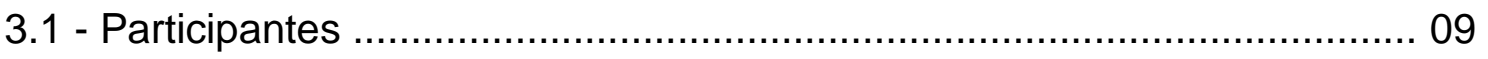

3.1 .1 - Critério de inclusão .................................................... 11

3.1.2 - Critério de exclusão …................................................... 11

3.2 - Equipamentos utilizados no estudo................................................... 12

3.2.1 - Aparelhos para avaliar o limiar de dor e estímulos dolorosos .... 12

3.2.2 - Aparelho para teste de atenção ....................................... 14

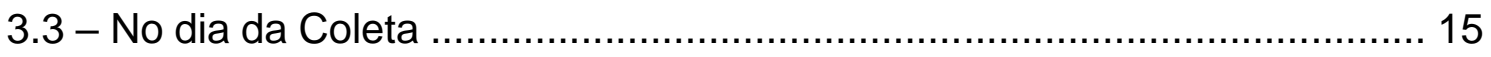

3.3.1 - Questionários de auto-aplicação........................................... 16

3.3.2 - Procedimentos de calibração ................................................. 18

3.3.3 - Treinamento do teste de atenção ...................................... 18

3.3.4 - Posicionamento do indivíduo ............................................. 19

3.3.5 - Aquisição de imagem ................................................... 19

3.4 - Análise de imagens de RMf .................................................... 21

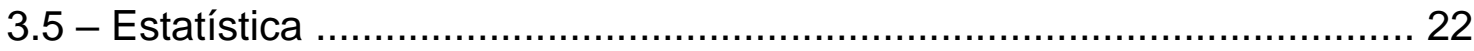




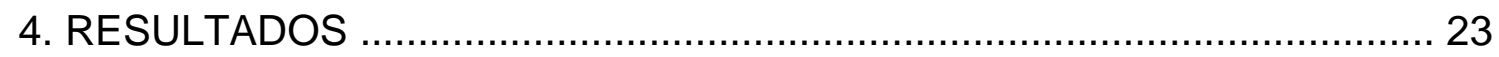

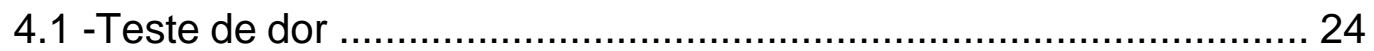

4.2 - Teste de Atenção (Stroop) ………………………………..... 27

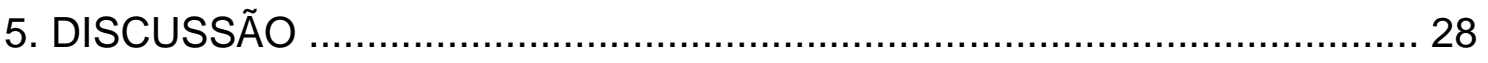

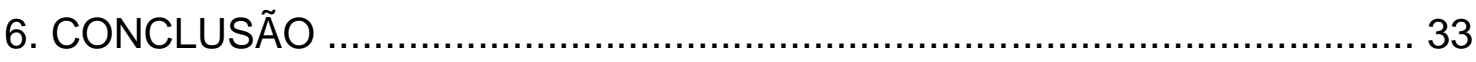

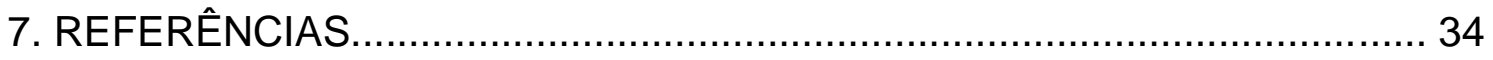

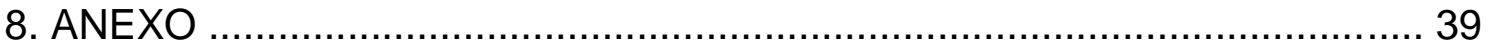




\section{Lista de abreviaturas}

LMC - Lombalgia Mecânica Comum

LMC/A - Lombálgicos com afastamento do trabalho

HIAE - Hospital Israelita Albert Einstein

RMf - Ressonância Magnética funcional

BOLD - Blood Oxygenation Level Dependent

CLBP - Chronic low back pain

INCE - Instituto do Cérebro do HIAE

END - Escala numérica de dor

STROOP - Teste de atenção

IDATE - Inventário de Ansiedade

IDATE-E - Inventário de ansiedade enquanto estado

IDATE-T - Inventário de ansiedade enquanto traço

FABQ - Fear Avoidance Questionnaire - questionário de medo evitação

IMC - Índice de massa corporal 


\section{Lista de figuras}

Figura 1: Fluxograma de recrutamento de voluntários ............................... 10

Figura 2: Plataforma e receptor de estímulos ...................................... 13

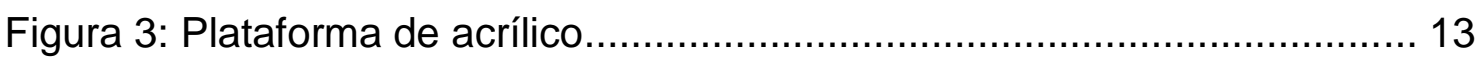

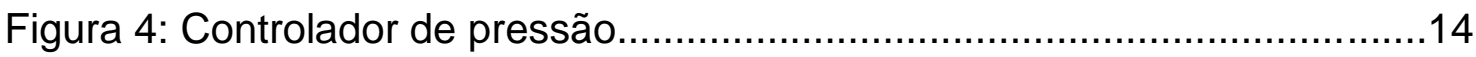

Figura 5 - Aparelho para programação do paradigma de dor (CACTUS) .........14

Figura 6: Caixa de botões para o teste de atenção (STROOP) .......................15

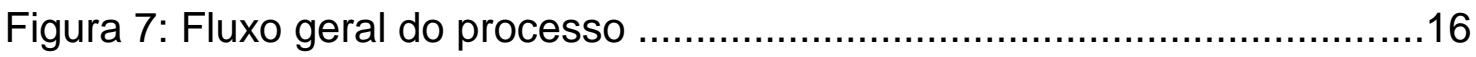

Figura 8: Bobina de cabeça de recepção de 12 canais (Siemens) e binóculo e caixa de gatilho da NNL Systems .................................................... 20

Figura 9: Efeito BOLD, após estimulação dolorosa, nos três grupos estudados, mostrou ativação nas áreas relacionadas à matriz de dor 25 Figura 10: Imagem 3D do cérebro que contém o resultado da análise de RMf no paradigma de dor na comparação de LMC > LMC/A 26

Figura 11: Imagem 3D do cérebro que contém o resultado da análise de RMf no paradigma de dor na comparação de controle $>$ LMC/A 27

\section{Lista de tabelas}

Tabela 1: Características dos grupos e resultados de testes de dor de pressão. 24 


\section{Resumo}

Feitosa ASA. Processamento da dor em indivíduos com lombalgia mecânica comum crônica, com e sem afastamento do trabalho: um estudo de ressonância magnética funcional [tese]. São Paulo: Faculdade de Medicina, Universidade de São Paulo; 2017.

A lombalgia mecânica comum (LMC) representa um problema particularmente importante no ambiente ocupacional, muitas vezes associado a incapacidade, afastamento do trabalho e alto custo socioeconômico. O surgimento da neuroimagem funcional permitiu novos conhecimentos sobre a estrutura cerebral e a fisiologia da dor crônica. Embora os aspectos relacionados ao trabalho sejam importantes fatores de risco para a cronicidade, existem poucos estudos que abordam especificamente a fisiopatologia da LMC em indivíduos afastados do trabalho. A esse respeito, questionamos se um fator como a atenção, conhecida como um importante modulador da dor, poderia desempenhar um papel distintivo na modulação da dor nos indivíduos com LMC afastados do trabalho. Objetivos: comparar os correlatos neuronais entre indivíduos com lombalgia mecânica comum com afastamento do trabalho, com indivíduos lombálgicos sem afastamento. Métodos: Foram selecionados 74 indivíduos com LMC crônica, divididos em três grupos: indivíduos com LMC e afastamento do trabalho $(\mathrm{LMC} / \mathrm{A})$; indivíduos com LMC sem afastamento do trabalho (LMC) e indivíduos sem qualquer tipo de dor crônica e sem afastamento do trabalho (Controle). O estudo foi realizado no Hospital Israelita Albert Einstein (HIAE). A ressonância magnética funcional (RMf) foi utilizada durante 0 desempenho de dois paradigmas (dor e atenção). Resultados: Após a estimulação dolorosa, na comparação entre os grupos, verificamos diferença significativa na condição estimulação > repouso, sendo que o contraste LMC > LMC/A mostrou maior resposta hemodinâmica (efeito BOLD) no córtex cingulado anterior e giro frontal superior e médio direito $(p<0,001)$. No contraste controles $>$ LMC/A, o grupo controle apresentou maior efeito BOLD em região do polo frontal e paracingulado $(p=0,002)$. Conclusão: Nosso estudo corrobora 0 conceito de que a presença de dor crônica está associada a uma alteração na 
plasticidade neuronal em áreas cerebrais que se estendem além das regiões somatossensoriais, para incluir áreas que processam emoções.

Descritores: Lombalgia mecânica comum crônica; Licença médica; Neuroimagem funcional; Resposta hemodinâmica; Plasticidade neuronal; Percepção da dor. 


\begin{abstract}
Feitosa ASA. Pain processing in individuals with chronic joint mechanical disease with and without work remission: a functional magnetic resonance imaging study [thesis]. São Paulo: "Faculdade de Medicina, Universidade de São Paulo"; 2017.
\end{abstract}

Chronic low back pain (CLBP) is a particularly important problem in the occupational environment, often associated with incapacity, sick leave and high socioeconomic cost. The emergence of functional neuroimaging allowed new insights into the brain structure and physiology of chronic pain. Although workrelated aspects are important risk factors for chronicity, there are few studies that specifically address the pathophysiology of CLBP in individuals with sick leave. In this regard, we questioned whether a factor such as the attention known as an important pain modulator could play a distinctive role in modulating pain in individuals with CLBP with sick leave. Objective The overall objective of this study is to compare the neuronal correlates between groups of individuals CLBP with or without sick leave. Methods We selected 74 individuals, divided into three groups: individuals with CLBP, functional incapacity and sick leave (CLBP_L); individuals with CLBP, functional disability without sick leave (CLBP_NL); individuals without any form of chronic pain and without sick leave (Control). Functional magnetic resonance imaging ( $f M R I)$ was used during the performance of two paradigms (pain and attention).Results After painful stimulation, a significant difference was observed in the stimulation> rest condition, while the CLBP > CLBP_L contrast showed a higher hemodynamic response in the anterior cingulate cortex and the right medium /superior frontal gyrus $(p<0.001)$ and in contrast controls > CLBP_L, the control group presented higher hemodynamic response in the frontal pole and paracingulate region $(p=$ 0.002).Conclusions Our study corroborates the idea that the presence of chronic pain is associated with an alteration in neuronal plasticity involving brain areas linked to emotions and not just somatosensory areas.

Descriptors: Low back pain mechanical chronic common; Sick leave; Functional neuroimaging; Hemodynamic response; Neuronal plasticity; Pain percep 


\section{INTRODUÇÃO}

Lombalgia pode ser definida como dor localizada entre o último arco costal e a prega glútea ${ }^{1}$. É uma das queixas mais comuns do ser humano, acometendo cerca de $80 \%$ da população mundial pelo menos uma vez ao longo da vida ${ }^{2}$.

Lombalgia pode ser classificada em aguda (com duração de 2 a 4 semanas), subaguda (com duração de até 12 semanas), ou crônica, quando a dor perdura por mais de 12 semanas ${ }^{1,3}$. A maioria dos episódios de lombalgia aguda são autolimitados. No entanto, recidivas são frequentes e cerca de $10 \%$ dos indivíduos evoluem com dor crônica ${ }^{1,2,3}$.

A dor lombar crônica pode ser causada por inúmeras doenças, incluindo, entre outras, patologias inflamatórias, degenerativas, neoplásicas e congênitas. No entanto, frequentemente, não existe uma boa correlação entre alterações anatômico-radiológicas e a sintomatologia. Mais do que uma exceção, esta é a situação mais comum nos casos de lombalgia crônica, constituindo uma entidade clínica denominada de lombalgia mecânica comum (LMC) ou lombalgia inespecífica ${ }^{1,3}$.

Devido a sua grande prevalência e impacto socioeconômico, a LMC tem sido alvo de inúmeras pesquisas que refletem o interesse acadêmico na identificação de fatores relacionados com a progressão para um padrão crônico de dor. Nesse sentido, vários estudos publicados reforçaram a importância dos fatores psicossociais na evolução da lombalgia aguda para a crônica ${ }^{1,4,5}$. Esses fatores têm sido conjuntamente denominados de "yellow flags" e incluem, entre outros, insatisfação no trabalho, ansiedade, depressão, medo, evitação e catastrofismo 4,5 . 
A LMC representa um problema particularmente importante no ambiente ocupacional, muitas vezes associado a deficiência e incapacidade ${ }^{6}$. O acometimento da população economicamente ativa está relacionado com altas taxas de absenteísmo e perda de produtividade ${ }^{7}$ e, consequentemente, elevado custo socioeconômico. Dados epidemiológicos recentes revelam que a lombalgia crônica é uma das causas mais comuns de incapacidade entre os adultos $^{7,8}$.

Desde a publicação de Waddel $^{9}$, em 1987, a correlação entre LMC e afastamento do trabalho foi fortemente enfatizada. Apesar de todos os esforços de prevenção, a prevalência de deficiência devido à LMC aumentou consideravelmente ao longo das últimas décadas ${ }^{3,10}$. No Brasil, acredita-se que o quadro seja bastante semelhante. O número de brasileiros incapacitados pela doença passou dos 10 milhões de pessoas ${ }^{11}$. Em 2007, foi a primeira causa de pagamento de auxílio-doença e a terceira causa de aposentadoria relacionada à incapacidade ${ }^{12}$. Segundo dados da Previdência Social, a dor nas costas é a doença que mais afasta trabalhadores, no Brasil, por mais de 15 dias. Em 2016, representou $4,71 \%$ de todos os afastamentos ${ }^{13}$.

A falta de uma melhor compreensão da fisiopatologia da LMC se reflete na alta taxa de recidiva e na resposta variável aos tratamentos medicamentosos e não medicamentosos habitualmente utilizados. Nesse sentido, a LMC tem sido vista, cada vez mais, como uma parte do espectro de outras situações clínicas também caracterizadas por dor crônica e fisiopatologia pouco conhecida.

A dor é uma experiência complexa e subjetiva, que engloba a interpretação de estímulos nociceptivos, influenciada por memórias, emoções, fatores patológicos, genéticos e $\operatorname{cognitivos}^{14}$. A Associação Internacional para 
Estudo da Dor define-a como "experiência emocional e sensorial subjetiva desagradável associada a real ou potencial lesão tecidual, ou descrito em termos de tal lesão".

Tradicionalmente, a dor é mensurada por escalas, por exemplo: visual analógica e numérica, cuja interpretação está sujeita a grande variabilidade individual ou cultural. Pesquisadores têm procurado demonstrar, por meio de exames de imagem, a forma como a dor altera o cérebro, na tentativa de obter uma leitura menos subjetiva da dor, bem como aprofundar o conhecimento dos mecanismos de processamento da mesma. Nesse sentido, técnicas de neuroimagem funcional têm sido amplamente utilizadas no estudo da dor crônica, inclusive com indivíduos de LMC, objetivando um melhor conhecimento da sua fisiopatologia.

A ressonância magnética funcional (RMf) é uma dessas técnicas, e permite detectar alteração de fluxo sanguíneo, o que reflete, indiretamente, a ativação neuronal ${ }^{15}$. A medida de RMf mais frequentemente utilizada baseia-se no chamado efeito BOLD (Blood Oxygenation Level Dependent). O sangue arterial e venoso (concentração de oxi-hemoglobina e desoxi-hemoglobina) comporta-se de forma diferente em um campo magnético. A atividade neuronal desencadeia uma alteração de fluxo sanguíneo que é desproporcionalmente maior do que aquela que o neurônio requer para realizar a função para a qual foi estimulado, permitindo que alterações na oxigenação de uma área específica do cérebro possam ser detectadas ${ }^{16}$. Em outras palavras, a RMf infere a atividade neuronal a partir de alterações localizadas no fluxo sanguíneo cerebral, em resposta a uma demanda metabólica. 
Imagens cerebrais podem ser obtidas em repouso e após realização de tarefa predefinida, permitindo coletar dados de todo o cérebro. Cada volume de elemento do cérebro avaliado na RMf é denominado de Voxel. Quando ocorrem alterações temporais coincidentes com o experimento realizado, testes estatísticos determinam se existe significância nas alterações observadas ${ }^{15}$.

O exame de RMf baseado em tarefa pode ser projetado com diversos desenhos de estudos denominados paradigmas. Os paradigmas são definidos como a construção, organização temporal e previsões comportamentais de tarefas cognitivas executadas pelo indivíduo durante o experimento, que devem ser definidos, para cada estudo, em função dos objetivos estabelecidos. Os estudos de RMf utilizam alguns tipos de paradigmas como:

1) - em bloco: onde o tempo de estímulo é igual ao tempo de repouso;

2) - evento relacionado: neste desenho, pode-se variar o tempo entre a apresentação e o intervalo dos estímulos, reduzindo a capacidade de o indivíduo prever quando e o que acontecerá, mantendo assim o nível de atenção ao longo do experimento. A principal vantagem desse paradigma é a capacidade de detectar variações transitórias nas respostas hemodinâmicas.

3) - evento relacionado rápido: é uma variação na qual o intervalo entre os estímulos é menor do que a duração da resposta hemodinâmica gerada a partir de estímulos anteriores.

4) - mistos: combinação de projetos relacionados ao bloco e ao evento. Pode fornecer informações relacionadas à atividade neuronal "mantida" versus "transitória" durante o desempenho do paradigma ${ }^{15}$.

Estímulos dolorosos transitórios ativam um grande conjunto de regiões cerebrais coordenadas entre si, independentemente da modalidade usada para 
provocar dor ${ }^{17}$. Essas regiões têm sido coletivamente denominadas matriz da dor, muito embora esse conceito não seja universalmente aceito. Apesar dessa ressalva, além de uma certa variação individual, a matriz da dor tem sido extensivamente estudada, incluindo áreas envolvidas em aspectos sensoriais discriminatórios da dor (córtex somatossensorial primário e secundário, tálamo e parte posterior da ínsula), bem como áreas implicadas em aspectos emocionais ou afetivos (córtex cingulado anterior, parte anterior da ínsula, córtex pré-frontal) ${ }^{14}$.

Nesse sentido, os estudos de RMf em condições de dor crônica trouxeram ainda maior complexidade ao conceito de matriz de dor ${ }^{17,18}$. Há evidências crescentes de uma plasticidade neuronal alterada na dor crônica. Os indivíduos com LMC crônica são mais sensíveis e ativam um maior número de áreas corticais relacionadas à matriz da dor, quando comparados com indivíduos sem dor, independente do estímulo utilizado (térmico ou de pressão de baixa intensidade) $)^{18,19}$.

A dor crônica também pode ser modulada por outros fatores como, por exemplo; atenção, expectativas e antecipação ${ }^{20}$. Vários estudos neurofisiológicos apoiam o papel da atenção e distração na modulação e ativação de diferentes partes da matriz da dor em resposta à dor evocada ${ }^{14,21}$. Uma ferramenta frequentemente utilizada para avaliar atenção em estudos neuropsicológicos é o teste de Stroop, que avalia a atenção seletiva, a capacidade de manter objetivos em uma atividade e a inibição da tendência para respostas impulsivas. O teste baseia-se na hipótese de que a velocidade no processamento da leitura de uma palavra é mais rápida do que o processo necessário para nomear a cor na qual a palavra está escrita. Desde que foi 
criado, em 1935, por John Stroop, vem apresentando diversas versões, denominadas genericamente paradigmas, sendo que o "Stroop Color World Test" (SCWT) é um dos mais utilizados em estudos de RMf21,22. Esse teste consiste em identificar a cor (vermelho, azul ou verde) de palavras escritas e apresentadas em três condições diferentes:

1 - Condição congruente: quando se apresenta o nome da cor escrito na mesma cor que ele representa (por exemplo: palavra vermelha escrita em vermelho)

2 - Condição neutra, quando apenas a palavra ou a cor são exibidas, sem nenhuma relação entre elas (por exemplo: lápis escrito em verde).

3 - Condição incongruente, quando se apresenta o nome da cor escrito em uma cor diferente daquela que ela representa (por exemplo: palavra vermelho escrita em verde). Neste caso ocorrerá um atraso no processamento da informação, um tempo de reação mais lento e uma maior possibilidade de erros.

O teste de Stroop é muito utilizado na RMf, em diferentes situações como, por exemplo: na avaliação de padrões de ativação cerebral e desempenho cognitivo e de analgesia induzida pela distração, em indivíduos fibromiálgicos ${ }^{21}$; na verificação de déficits de tomada de decisão e aprendizagem associativa em indivíduos com fibromialgia ${ }^{23}$; no exame da relação entre dor e função executiva em indivíduos com artrite reumatóide ${ }^{24}$. No entanto, existem poucos estudos com lombálgicos durante o processamento de atenção.

Embora a RMf tenha fornecido novos conhecimentos sobre as condições de dor crônica, a identificação de subgrupos com LMC continua sendo um desafio. Aspectos relacionados ao trabalho são reconhecidamente fatores 
importantes para a cronicidade, mas poucos estudos abordaram especificamente a fisiopatologia da LMC em indivíduos afastados do trabalho. Assim sendo, questionamos se a atenção, poderia desempenhar um papel distintivo na modulação da dor deste subgrupo de indivíduos, quando comparados, estes, com lombálgicos sem afastamento do trabalho e saudáveis.

\section{Hipótese do estudo}

Individuos com LMC crônica afastados do trabalho, apresentem respostas hemodinâmicas cerebrais (efeito BOLD) distintas dos lombálgicos crônicos sem afastamento do trabalho e indivíduos sem dor quando submetidos a testes de dor, com estímulo de pressão e intensidade de dor moderada; e teste de atenção (Stroop). 


\section{OBJETIVOS}

Geral: comparar os correlatos neuronais entre indivíduos com LMC afastados do trabalho por causa da dor lombar, com indivíduos com LMC sem afastamento do trabalho.

Específicos: Descrever o padrão de atividade cerebral dos grupos de indivíduos com LMC (com e sem afastamento do trabalho) em dois paradigmas: dor e atenção.

Verificar se há aumento da atividade neuronal nas áreas relacionadas à atenção no grupo de indivíduos afastados do trabalho, em relação aos outros dois grupos.

Comparar a atividade cerebral do grupo de LMC com indivíduos saudáveis no paradigma de dor e de atenção. 


\section{MÉTODOS}

Tipo de estudo: Observacional

\section{1 - Participantes}

O estudo foi realizado no Hospital Israelita Albert Einstein (HIAE). Os voluntários foram recrutados no ambulatório de Reumatologia do Hospital das Clínicas da Faculdade de Medicina da Universidade de São Paulo (HCFMUSP), Departamento de Fisioterapia do HIAE e através de anúncios feitos nessas duas instituições.

Após a seleção dos possíveis voluntários, as enfermeiras do departamento de pesquisa do Instituto do Cérebro (INCE) do HIAE, entraram em contato via telefone ou e-mail com 237 indivíduos. Um total de 135 não atenderam aos critérios de inclusão descritos na sequência e foram excluídos. Foram agendados 102 voluntários, para consulta com o reumatologista para confirmação do diagnóstico de LMC crônica. Após a avaliação médica, realizada na unidade de reumatologia ambulatorial do HCFMUSP, foram excluídos mais 24 voluntários. Setenta e oito indivíduos foram selecionados para o estudo. Quatro indivíduos não toleraram o procedimento $\mathrm{RMf}$ e foram retirados do estudo. Setenta e quatro voluntários, destros, (44 mulheres e 30 homens) completaram o estudo [figura1]. Todos os indivíduos assinaram o termo de consentimento livre e esclarecido [Anexo1]. O estudo foi aprovado pelo Comitê de Ética de ambas as instituições (CAPPesq 0186/11 e CEP/Einstein no10/1480) [Anexo 2 e 3]. 
Nossa amostra foi limitada a um número máximo de 25 indivíduos por grupo, em função da complexidade logística necessária. Thirion et al. ${ }^{25}$, concluíram ser necessário um mínimo de 20 indivíduos por grupo, em estudos de neuroimagem funcional, para ter confiabilidade suficiente.

Figura 1: Fluxograma de recrutamento de voluntários

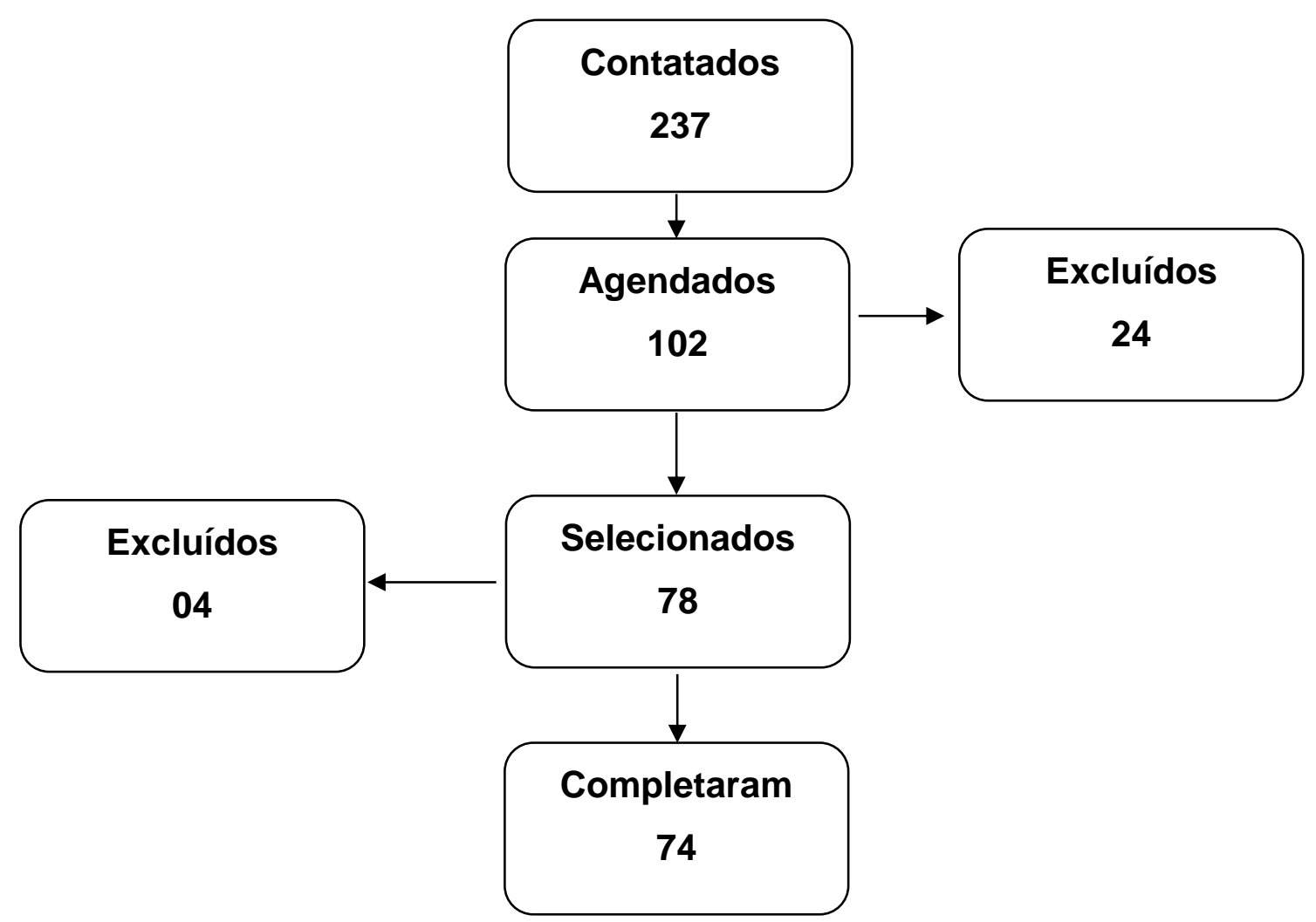

Os indivíduos foram alocados em três grupos:

1. LMC crônica, incapacidade funcional e afastamento do trabalho (LMC/A);

2. LMC crônica, incapacidade funcional sem afastamento do trabalho (LMC);

3. Indivíduos sem qualquer tipo de dor crônica ou afastamento do trabalho por causa da dor (Controle). 


\subsection{1 - Critério de inclusão}

\section{Grupo de indivíduos LMC/A e LMC}

1 - Dor localizada entre as últimas costelas e as pregas glúteas, por mais de 12 semanas

2 - Escala numérica de dor (END) nos últimos 7 dias $\geq 5$

3 - Deficiência funcional definida por uma pontuação $\geq 10$ no questionário Rolland Morris ${ }^{26}$ [Anexo 4]

4 - Indivíduos em afastamento trabalhista temporário ou definitivo, requisitando esse afastamento como consequência de incapacidade funcional relacionada com dor lombar crônica, exceto para o grupo LMC

5 - Idade entre 35 a 60 anos

6 - Destros

\section{Grupo Controle}

1 - Idade superior a 35 anos a 60 anos

2 - Ausência de dor lombar ou qualquer outra forma de dor crônica

3 - Ausência de afastamento do trabalho

4 - Destros

\subsection{2 - Critério de exclusão}

1 - Diagnóstico de doença das articulações inflamatórias

2 - Dor lombar com irradiação para os membros inferiores abaixo dos joelhos

3 - Diagnóstico de estenose do canal espinhal

4 - História de cirurgia da coluna

5 - Diagnóstico de osteoartrite de membro inferior sintomático 
6 - Fraturas vertebrais atuais ou anteriores

7 - Diagnóstico atual ou prévio de neoplasia

8 - Doença crônica subjacente descompensada que, no julgamento médico, prejudicaria a análise

9 - Analfabetos ou incapazes de entender as instruções

\section{2 - Equipamentos utilizados no estudo}

\subsection{1 - Aparelhos para avaliar o limiar de dor e estímulos dolorosos}

Para a realização deste estudo foi desenvolvido um novo sistema de estimulação por pressão adequado a estudos de RMf, capaz de gerar estímulos de dor controlados com sincronização precisa com a aquisição da imagem.

Dois aparelhos semelhantes foram confeccionados pela empresa (Zurc\&Zurc, São Paulo, Brasil) sob supervisão da equipe do estudo. Foram desenvolvidos com base em um aparelho similar usado por Gracely et al. ${ }^{27}$, destinado a sincronizar com precisão os estímulos dolorosos da pressão com a aquisição da imagem RMf. O primeiro aparelho (A1) de estímulo pressórico com objetivo de avaliar o limiar de dor foi confeccionado em metal [figura 2], para ser utilizado externamente ao ambiente da ressonância magnética. O segundo aparelho (A2) destinado a provocar estímulos pressóricos durante a coleta de dados foi confecionado em acrílico para ser utilizado durante a coleta de imagens na RMf [figura 3].

O A1 é composto por uma plataforma onde são colocados pesos para calibragem do sistema. A plataforma é conectada por um circuito hidráulico a uma seringa com água que é manualmente acionada para exercer pressão. $O$ 
sistema também é conectado a uma caixa, onde o indivíduo coloca o polegar esquerdo, e o aparelho exerce uma pressão.

O A2 funciona de forma semelhante, porém é acionado através de um sistema de ar comprimido. Durante a coleta de dados, o indivíduo segura um bastão para posicionamento do polegar esquerdo dentro de uma caixa onde um êmbolo exercerá a pressão. O êmbolo é conectado a outros êmbolos através de um sistema hidráulico e a uma combinação de válvulas. Dessa forma, é possível reproduzir estímulos controlados e repetitivos quando pesos são aplicados à plataforma. Os aparelhos utilizados possuem objetivos diferentes, por isso foi possível a confecção em materiais diferentes, sem influenciar o resultado.

Figura 2. Plataforma e receptor de estimulo

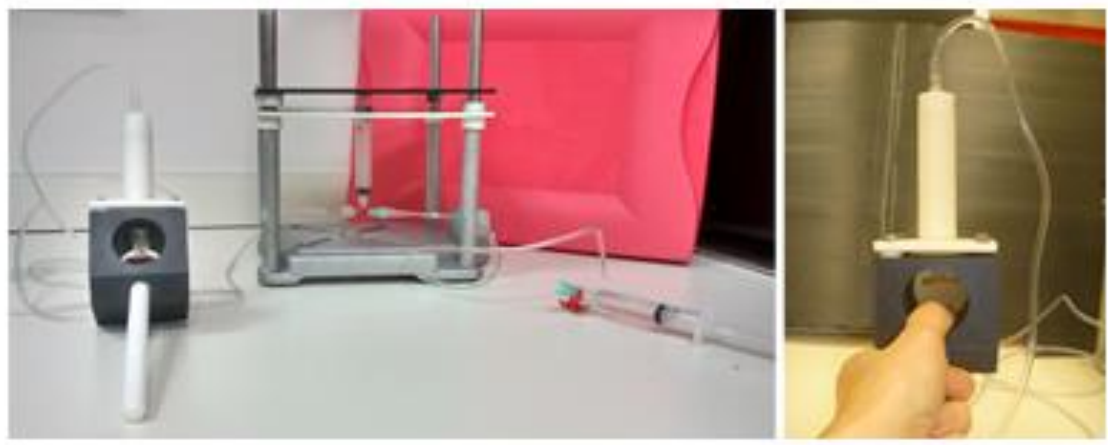

Figura 3: Plataforma de acrílico
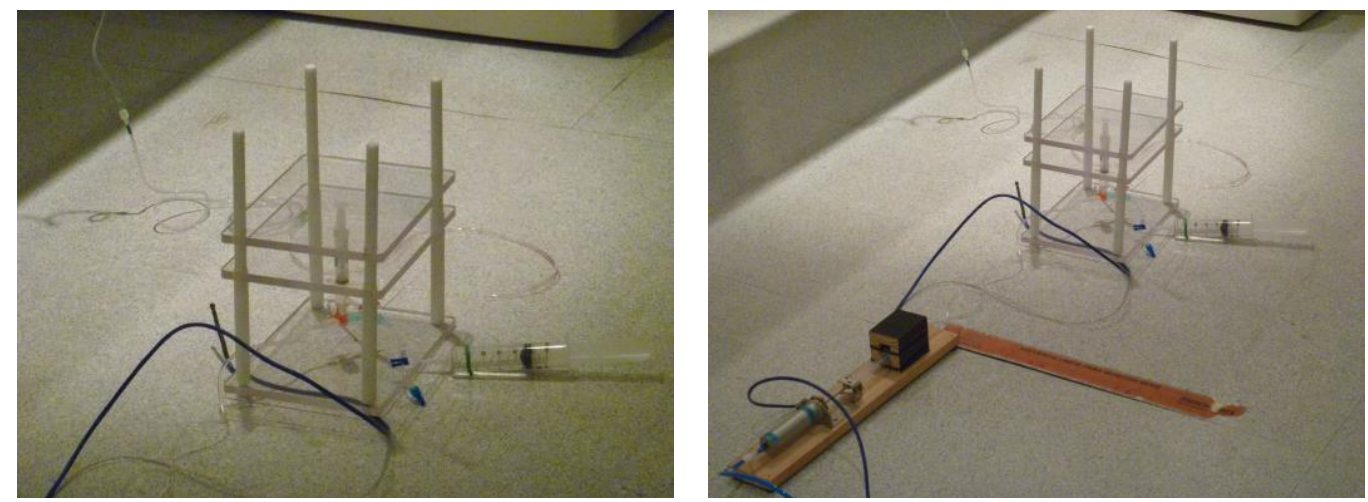
Na figura 4, observa-se o sistema de controle de entrada e saída do ar comprimido para exercício de pressão.

Figura 4. Controlador de pressão

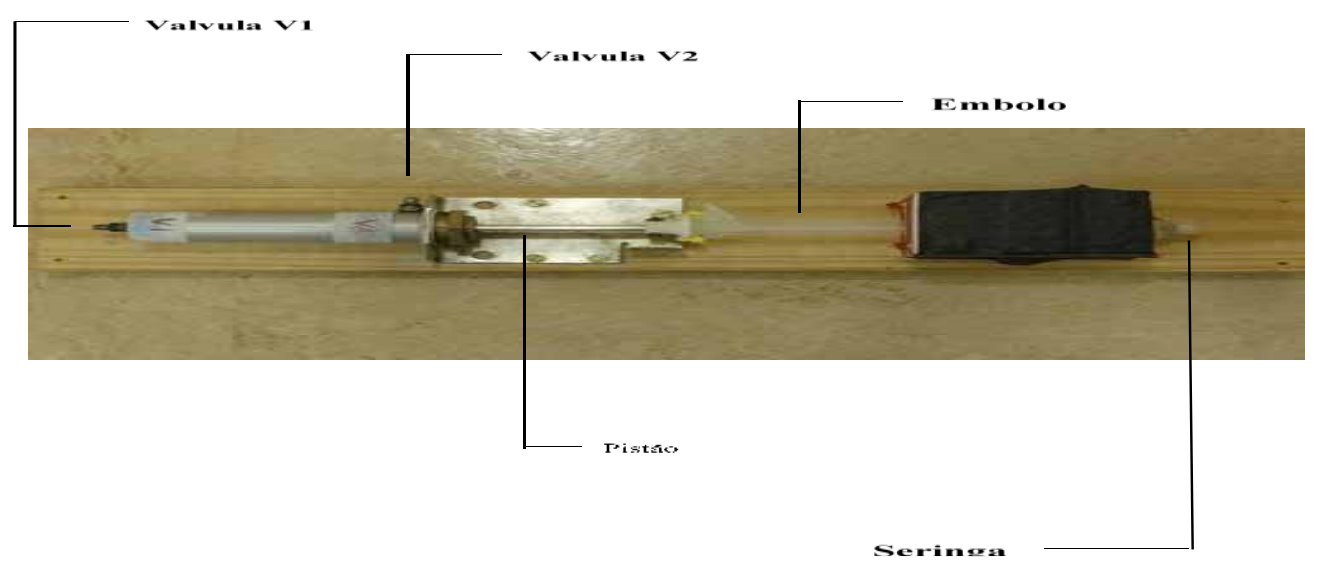

Na figura 5, observa-se a central de comando denominada de CACTUS. Esse instrumento é responsável pela sincronização entre estímulo de dor e aquisição de imagem RMf. É um sistema de produção de estímulo de dor que é controlado para cada experimento.

Figura 5 - Aparelho para programação do paradigma de dor (Compressed Air Controlled Tactile Universal Stimulus - CACTUS)

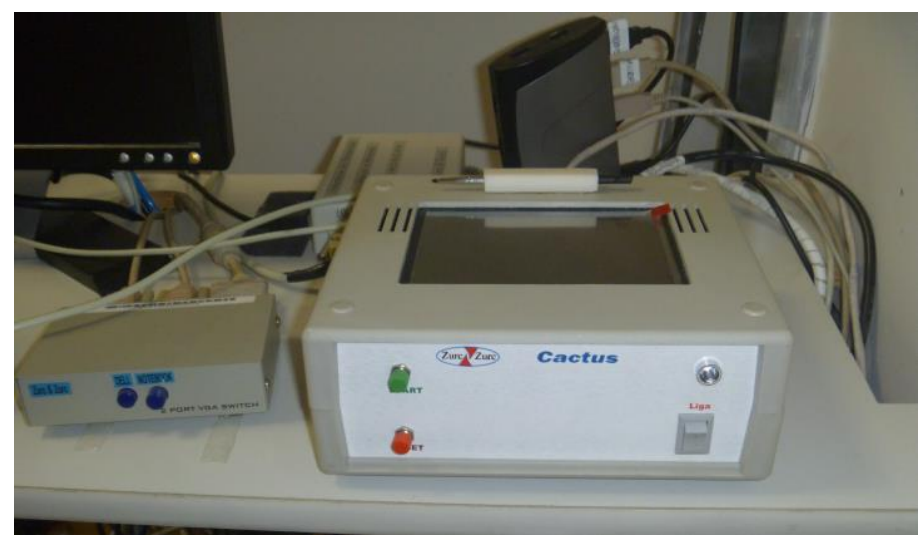


3.2.2 - Aparelho para teste de atenção: para receber e registrar as respostas do sujeito ao teste de atenção (STROOP) foi utilizada uma caixa de resposta com três botões (Zurc\&Zurc, São Paulo, Brasil). Trata-se de uma interface de resposta motora compatível com o alto campo magnético da RM. Os botões receberam cores respectivas à resposta do teste (azul, vermelho e verde) [figura $6]$.

Figura 6: Caixa de botões para o teste de atenção (STROOP)

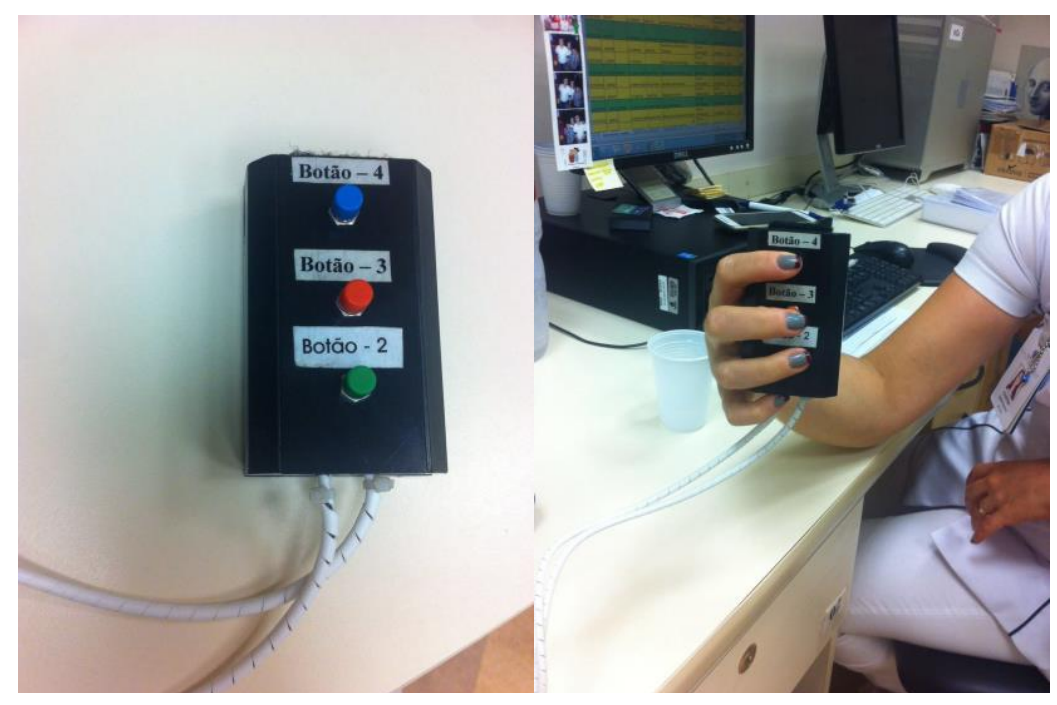

\section{3 - No dia da Coleta}

Os voluntários foram registrados na recepção do INCE do HIAE, trajados apropriadamente (roupa utilizada em exames de ressonância magnética), responderam alguns questionários (classificação socioeconômica, Inventário de Depressão Beck, Inventário de Ansiedade e medo-evitação), realizaram préteste para avaliar o limiar de dor e treinamento para o teste de atenção (Stroop) [figura7]. 
Figura 7: Fluxo geral do processo

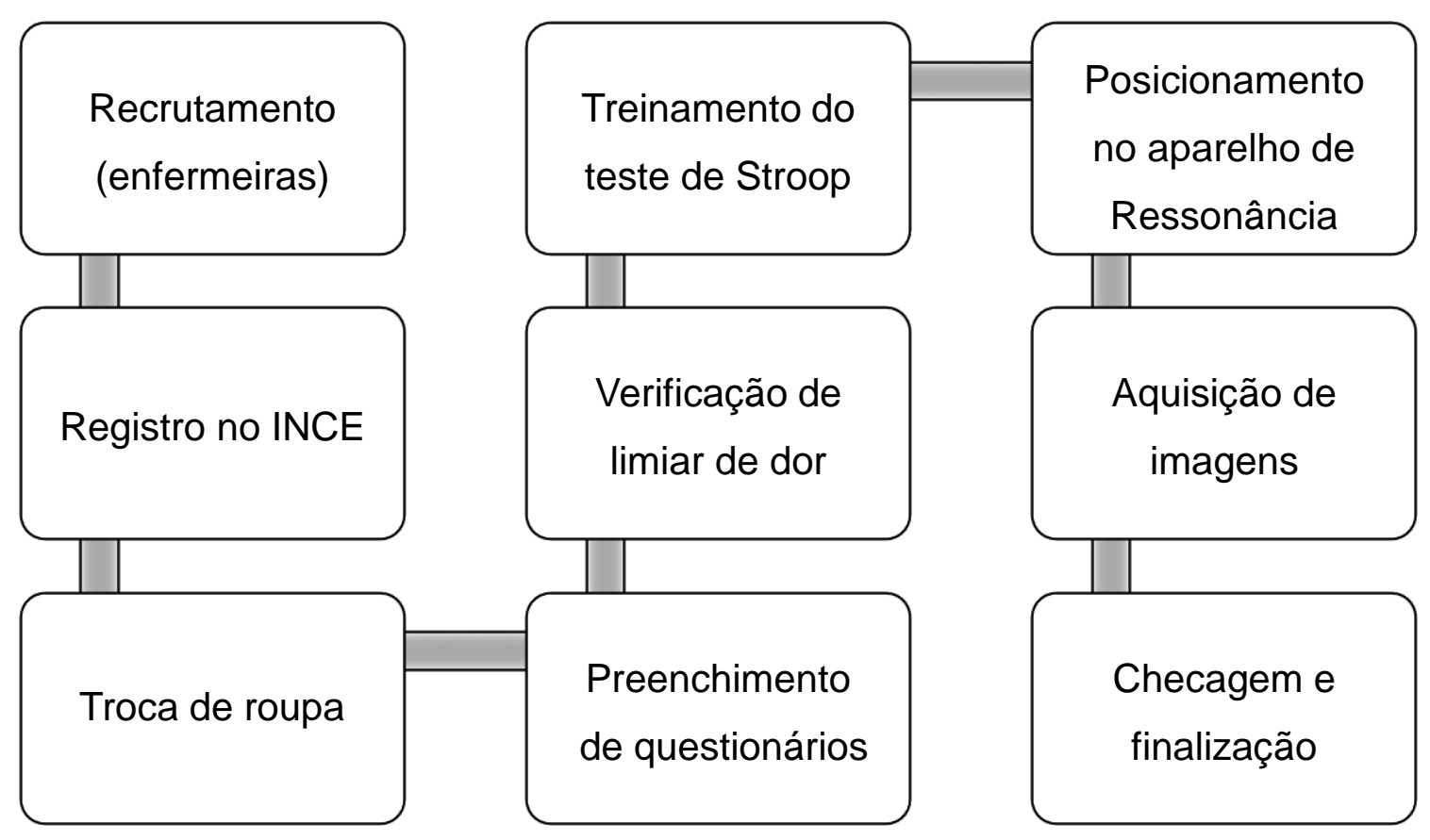

3.3.1 - Questionários de autoaplicação: Os voluntários responderam aos seguintes questionários previamente validados.

Questionário de classificação socioeconômica: (ABA-ABIPEME Critério da Associação Brasileira de Anunciantes - Associação Brasileira de Institutos de Pesquisa de Mercado, Brasil 2008). A classificação socioeconômica da população é apresentada por meio de oito classes, denominadas A1, A2, B1, B2, C1, C2, D e E correspondendo, respectivamente, a uma pontuação determinada $(0-46)^{28}[$ Anexo 5]. 
Inventário de Depressão Beck: composto por 21 itens com pontuações variando de 0 a 63. Cada item comporta quatro afirmações que variam quanto à intensidade ( 0 a 3), cabendo ao respondente indicar qual das quatro afirmações melhor descreve os seus sintomas. Pontuações acima de 15 denotam sintomas depressivos $^{29}[$ Anexo 6].

Inventário de Ansiedade (IDATE): dividido em dois questionários; ansiedade como estado (IDATE-E) e ansiedade enquanto traço (IDATE-T). O estado de ansiedade reflete uma reação transitória diretamente relacionada a uma situação de adversidade, enquanto o traço de ansiedade se refere a um aspecto mais estável, relacionado à propensão do indivíduo ao longo de sua vida. A escala estado requer que o participante descreva como se sente "agora, neste momento" em relação a 20 itens apresentados em uma escala Likert de 4 pontos: 1- absolutamente não; 2-um pouco; 3- bastante; 4- muitíssimo. De maneira semelhante, a escala traço também é composta de 20 itens, mas o participante recebe a instrução de que deve responder como "geralmente se sente", de acordo com uma nova escala Likert de 4 pontos: 1- quase nunca; 2- às vezes; 3- frequentemente; 4- quase sempre. A pontuação varia de 20 a 80 pontos e valores mais altos indicam níveis mais altos de ansiedade ${ }^{30}$ [Anexo 7 e 8].

Questionário de medo - evitação (Fear Avoidance Questionnaire - FABQ): O FABQ é constituído por 16 itens, que são divididos em duas subescalas: a que aborda os medos e as crenças dos indivíduos em relação a atividades físicas (FABQ-Phys) e ao trabalho (FABQ-Work). Cada item é graduado em uma escala de sete pontos, que varia de 0 (discordo completamente) a 6 (concordo completamente). Para diferenciar os medos e crenças em relação às atividades físicas e ocupacionais, o escore deve ser obtido isoladamente em cada uma das 
subescalas. Índices maiores que 15 para a atividade física e maiores que 34 para o trabalho são considerados indicadores para a crença de medo e evitação ${ }^{31}$ [Anexo 9].

\subsection{2 - Procedimentos de calibração (limiar de dor)}

O aparelho A1 foi utilizado para verificar o valor do limiar de dor do indivíduo. Este teste foi realizado em uma sala ao lado do equipamento de ressonância magnética e previamente à aquisição das imagens.

A sensibilidade dolorosa à pressão foi avaliada por escala numérica de dor descritora de intensidade e desconforto variando de 0 a 10 . Os indivíduos foram submetidos a estímulos pressóricos crescentes, aplicados ao polegar esquerdo, com auxílio do aparelho A1 (começando com $1 \mathrm{~kg}$ e aumentado gradualmente de $0,5 \mathrm{~kg}$ em 0,5kg, até a tolerância ou peso máximo de $7 \mathrm{~kg}$ ). A pressão capaz de produzir uma dor de intensidade média ( 5 a 7 pontos no END) foi inicialmente escolhida para a segunda fase da coleta de dados.

Um estudo piloto mostrou que os indivíduos submetidos a repetidos estímulos de dor desenvolveram habituação à dor e reduziram a intensidade de dor percebida em comparação com o teste inicial. Quando adicionamos $1 \mathrm{~kg}$ ao total, manteve-se a intensidade moderada da dor. Portanto, escolhemos sempre adicionar $1 \mathrm{~kg}$ ao valor final obtido no teste inicial para garantir que todos tenham recebido um estímulo de dor supralimiar.

\subsection{3 - Treinamento do teste de atenção}

Para o treinamento da tarefa de Stroop, o indivíduo escolhia entre três botões com cores distintas (verde, vermelho e azul). Os indivíduos foram 
instruídos a comunicar a cor da tinta de palavras simples apresentadas em três condições: congruente (a cor e a palavra são iguais, por exemplo, "azul" na cor azul), neutro (palavras não relacionadas a qualquer cor, por exemplo "lápis" em azul) e incongruente (a cor e a palavra são diferentes, por exemplo, "azul" em tinta verde) pressionando um dos 3 botões na caixa de resposta na mão direita. O treinamento foi realizado até que o voluntário se sentisse seguro na realização da tarefa.

\subsection{4 - Posicionamento do indivíduo}

Os indivíduos foram posicionados no aparelho de ressonância magnética em decúbito dorsal. Na mão direita foi colocada a caixa de resposta para o teste de Stroop e no polegar esquerdo o dispositivo de pressão. As informações para cada teste foram visualizadas através de um binóculo e as instruções foram transmitidas aos voluntários por um fone de ouvido. A coleta de dados durou aproximadamente 50 minutos, incluindo protocolos da ressonância e a realização dos testes de dor e de atenção.

\subsection{5 - Aquisição das imagens}

Todas as imagens foram adquiridas em 3,0 Tesla MR System (Siemens Tim Trio, Erlangen, Alemanha), localizado no setor de ressonância magnética do HIAE com a versão de software Syngo B15, utilizando-se de bobina de cabeça de 12 canais [figura 8]. 
Figura 8: Bobina de cabeça de recepção de 12 canais (Siemens) e binóculo e caixa de gatilho da NNL Systems
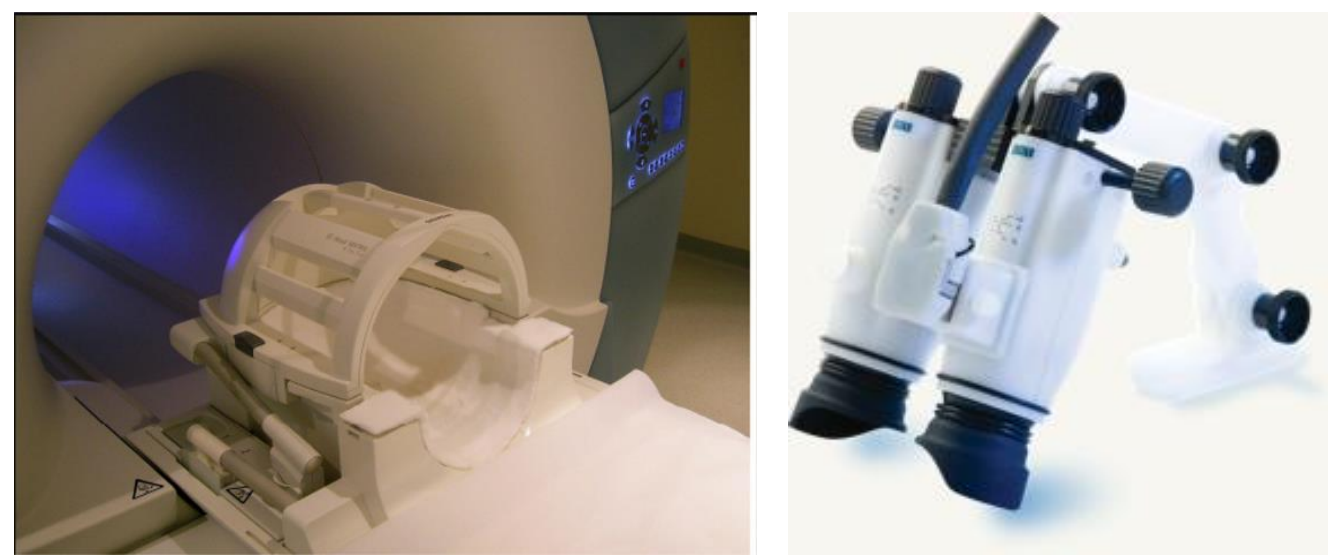

Fonte: http://www.mdpi.com/1424-8220/10/6/5724/htm e http://www.nordicneurolab.com

A apresentação do estímulo visual e a sincronização da resposta do assunto foram feitas usando binóculo e caixa de gatilho da NNL Systems (Nordic Neuro Lab, Bergen, Noruega) [figura 8]. A aquisição do RMf baseou-se em imagens T2 positivas de echo planar (EPI) para todo o cérebro. Foram adquiridas 32 fatias axiais após a angulação AC-PC. Os parâmetros de aquisições para RMf foram: $\mathrm{TR}=2000 \mathrm{~ms}, \mathrm{TE}=30 \mathrm{~ms}, 3,2 \mathrm{~mm}$ de espessura da fatia, $0,8 \mathrm{~mm}$ de intervalo interstício, FOV $=210 \mathrm{~mm}$, matriz 64X64 (Voxel isotrópicos), descartando os primeiros 4 volumes necessários para que o sinal RM atingisse o estado estacionário. Também recolhemos a imagem estrutural sagital de alta resolução T1 com 192 fatias para corregistro com os dados seguinte da RMf. Parâmetros: volPEL isotrópico (1) MO-WP ponderado (MPRAGE), TR $=2500$ $\mathrm{ms}, \mathrm{TE}=3,45 \mathrm{~ms}, \mathrm{FOV}=265 \mathrm{~mm}, \mathrm{IR}=1100$, ângulo de inclinação de 7 graus.

No teste de dor, utilizamos um paradigma de evento relacionado. A dor (pressão) foi mantida constante durante 2 s, correspondendo a 1 volume, sendo 14 estímulos de dor com intervalo de 24s de um estímulo para o outro. A duração de aquisição foi de 180 volumes/360s. No teste de atenção (Stroop), utilizamos 
um paradigma de bloco cada palavra foi apresentada por 1s, intercalada por uma cruz de fixação por 1s. Cada condição foi apresentada 10x por rodada, em blocos de 15 ensaios na sequência congruente - neutro - incongruente. A duração de aquisição foi de 150 volumes/300s. O paradigma foi programado em sistema já em uso no departamento (Eprime, Psylabs), sincronizando a apresentação do estímulo com a aquisição das imagens e resposta do indivíduo, via botão.

\section{4 - Análise de imagens de RMf}

Após a aquisição, as imagens foram transferidas para o servidor do Instituto do Cérebro (Data Center). Um computador de alta performance (MacPro Core Intel Xeon, Macintosh - Apple, California, EUA) foi utilizado para as análises de RMf. Primeiramente, o programa MRI Convert (Lewis Center for Neuroimaging, Oregon, EUA) foi utilizado para conversão das imagens DICOM retiradas da máquina em arquivos nifti (nii) utilizados pelos programas estatísticos. O processamento de dados e as análises estatísticas foram realizadas com FSL (www.fmrib.ox.ac.uk/fsl/). Os volumes foram processados por correção de movimento (MCFLIRT), corte de filtro de passagem alta (50s), suavização espacial (FWHM $=5 \mathrm{~mm}$ ) e normalização espacial para espaço padrão (affine, 12 DoF). A inferência estatística foi corrigida para múltiplas comparações. Os mapas de ativação foram produzidos com a utilização do modelo linear geral (GLM), que se baseiam na estimativa semiparamétrica de auto correlação residual ${ }^{32}$.

Determinamos regiões cerebrais mais ativas no incongruente em relação ao congruente. Todas as imagens estatísticas foram consideradas pelo uso da inferência gaussiana aleatória de campo com base em campo com um limite de 
Z> 2,3 no nível de Voxel e um limite de significância de cluster corrigido de $\mathrm{P}$ $<0,05$. Análises de clusters sobreviventes a análise de grupo, foram interrogadas pela ferramenta Featquery e as médias de ativação comparadas. Uma análise de covariância foi realizada considerando o peso aplicado durante o teste. A teoria FDR (Taxa de descoberta falsa) foi usada para realizar a correção de comparação múltipla.

\section{5 - Estatística}

As variáveis categóricas estão descritas por frequências absolutas e relativas, enquanto que as numéricas, por mediana e intervalo interquartil $\left(1^{\circ} \mathrm{e}\right.$ $3^{\circ}$ quartis). Para comparar as variáveis categóricas, utilizaram-se testes exatos de Fisher. Para as variáveis numéricas, utilizaram-se testes de Kruskal-Wallis para comparar três grupos e testes de Mann-Whitney para dois grupos.

Para a comparação entre os grupos, nas diferentes fases do teste Stroop, ajustamos um modelo misto generalizado com distribuição binomial e um efeito aleatório, considerando a dependência entre medidas do mesmo indivíduo em diferentes testes. Os resultados foram apresentados para odds ratios estimados, intervalos de confiança de $95 \%$ e valores de p. No caso do tempo de resposta, a distribuição que melhor se adequava aos dados era inversa normal, e os modelos misturados generalizados foram ajustados com esta distribuição separadamente, por grupos de sucesso e de erro. Foi utilizado o pacote computacional R 3.1.3 (R Core Team, 2015). O nível de significância adotado foi de $5 \%{ }^{33-35}$. 


\section{RESULTADOS}

Setenta e quatro indivíduos foram incluídos e divididos em três grupos: LMC/A $(N=24), \operatorname{LMC}(n=25)$ e controles $(n=25)$. Não foram observadas diferenças significativas na média de idade ( $48,5 \pm 5,7$ vs. $48 \pm 6$ vs. $45 \pm 7$ anos, $p=0,530)$ e sexo feminino $(41,7 \%$ vs. $68 \%$ vs. $68 \%, p=0,097)$, tabela 1 .

No grupo LMC/A nenhum indivíduo estava afastado do trabalho definitivamente. Dez (42\%) estavam afastados por mais de 5 anos e 14 (60\%) não estavam recebendo nenhum benefício (auxílio-doença).

$\mathrm{Na}$ tabela 1 observamos que os grupos foram homogêneos quanto ao índice de massa corporal (IMC) e classificação socioeconômica. Nos dois grupos de indivíduos lombálgicos não houve diferença significativa na END e FABQphysic (medo-evitação de atividade física).

O grupo LMC/A foi significativamente mais depressivo $(p=0,030$ vs. controle), teve menor nível de escolaridade ( $p=0,010$ vs. LMC) e ( $p=0,048$ vs. controle), apresentou maior incapacidade funcional medida por QRM ( $p=0,003$ vs. $L M C$ ), níveis mais altos no IDATE-T ( $p=0,004$ vs. $L M C$ e $p=0,033$ vs. controle) e IDATE-E ( $p<0,001$ vs. LMC e $p<0,001$ vs. controle) e maior FABQwork ( $p=0,001$ vs. LMC). Todas as perguntas do FABQ-work foram analisadas individualmente e foram significativamente mais frequentes no grupo LMC/A do que no grupo LMC. O peso médio utilizado para provocar dor de intensidade moderada foi menor para LMC ( $p<0,001$ vs. controles). 
Tabela 1: Características dos grupos e resultados de testes de dor de pressão

\begin{tabular}{|c|c|c|c|c|c|}
\hline \multicolumn{2}{|c|}{ Variáveis } & LMC/A ( $n=24)$ & LMC $(n=25)$ & Controle $(n=25)$ & Valor "P" \\
\hline \multicolumn{2}{|c|}{ Sexo F (\%) } & $10(41,7)$ & $17(68,0)$ & $17(68)$ & 0,097 \\
\hline \multicolumn{2}{|c|}{ Idade (anos) } & $48,5(42,8-53,2)$ & $48(42-54)$ & $45(38-52)$ & 0,530 \\
\hline \multicolumn{2}{|c|}{ IMC (Kg / m2) } & $27,5(25,1-29,6)$ & $26,3(24,8-29,5)$ & $25,8(24,6-29)$ & 0,678 \\
\hline & $\mathrm{A} 1$ & $1(4,3)$ & $1(4,2)$ & $0(0,0)$ & 0,311 \\
\hline & $\mathrm{A} 2$ & $0(0,0)$ & $3(12,5)$ & $2(8,0)$ & \\
\hline Classificação & B1 & $1(4,3)$ & $5(20,8)$ & $6(24,0)$ & \\
\hline socioeconômica & B2 & $7(30,4)$ & $7(29,2)$ & $9(36,0)$ & \\
\hline \multirow[t]{3}{*}{$(\%)$} & C1 & $6(26,1)$ & $5(20,8)$ & $6(24,0)$ & \\
\hline & $\mathrm{C} 2$ & $4(17,4)$ & $2(8,3)$ & $0(0,0)$ & \\
\hline & D & $4(17,4)$ & $1(4,2)$ & $2(8,0)$ & \\
\hline \multicolumn{2}{|c|}{ Educação (anos) } & $10,5(8-11) \mu ¥$ & $11(11-15)$ & $11(9-15)$ & 0,025 \\
\hline \multicolumn{2}{|c|}{ Incapacidade (QRM) } & $18(17-19,8)$ & $14,00(11-16,8)$ & & 0,003 \\
\hline \multicolumn{2}{|l|}{ END } & $8(8-8,75)$ & $8(6,5-8,7)$ & & 0,709 \\
\hline \multicolumn{2}{|c|}{ Sintomas depressivos - N (\%) } & $12(50,0)$ & $8(33,3)$ & $3(12,0) \#$ & 0,016 \\
\hline \multicolumn{2}{|c|}{ IDATE-T } & $50,5(41,5-55,5)$ & $42(35,7-52) \beta$ & $34(30-43) \Omega$ & $<0,001$ \\
\hline \multicolumn{2}{|c|}{ IDATE-E } & $45(37,7-51)$ & $39(35,5-42) \beta$ & $38(30-45) \beta$ & 0,019 \\
\hline \multicolumn{2}{|c|}{ FABQ-physic } & $18(10-22,2)$ & $10,5(3-17,2)$ & & 0,056 \\
\hline \multicolumn{2}{|c|}{ FABQ-work } & $33,5(26,8-39,8)$ & $15,5(5,2-31)$ & & 0,001 \\
\hline \multicolumn{6}{|c|}{ Peso utilizado para verificar o } \\
\hline limite de do & & $5(4,5-7,5)$ & $5(4,5-6)$ * & $7(5,5-7,5)$ & 0,008 \\
\hline
\end{tabular}

As variáveis são descritas por frequências absolutas e relativas ( $\mathrm{n} \%$ ). As variáveis numéricas são expressas pela faixa mediana e interquartil (1ํ e $3^{\circ}$ quartis) / LMC/A: indivíduos com dor lombar e afastamento do trabalho / LMC: indivíduos com dor lombar / valor $P$ : teste de hipótese de diferença entre os três grupos e suas categorias

$¥ \mathrm{P}<0,050$ em comparação LMC $\boldsymbol{\mu} \mathrm{P}=0,010$ em comparação controle $\# \mathrm{P}<0,030$ em comparação LMC/A

$\boldsymbol{\beta} P<0,005$ em comparação LMC/A

$\Omega \mathrm{P}<0,050$ em comparação LMC/A

${ }^{*} P<0,001$ em comparação Controle

\section{1 -Teste de dor}

Os três grupos de estudo mostraram efeito BOLD evocado por dor de pressão em áreas relacionadas à matriz de dor: S1, S2, tálamo, ínsula, córtex pré-frontal e córtex cingulado anterior [figura 9]. 
Figura 9: Efeito BOLD, após estimulação dolorosa, nos três grupos estudados, mostrou ativação nas áreas relacionadas à matriz de dor

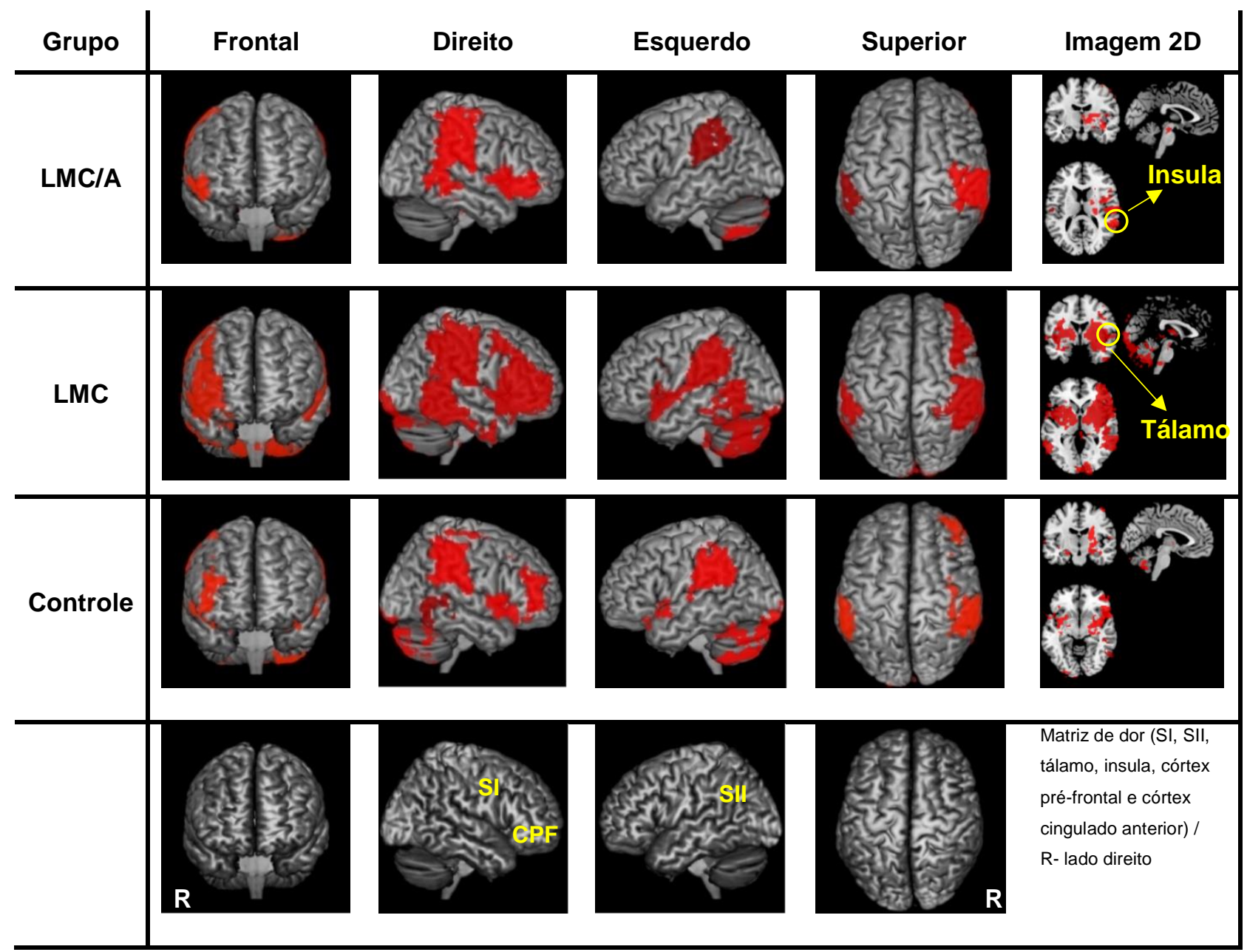

A análise entre os grupos com covariação para o peso utilizado para os estímulos de dor mostrou diferenças significativas na condição estimulação> repouso; O contraste $L M C>L M C / A$ mostrou maior efeito BOLD no córtex cingulado anterior e giro frontal superior e médio direito $p<0,001$ [figura 10]. 
Figura 10: A-) Imagem 3D do cérebro que contém o resultado da análise de RMf no paradigma da dor na comparação LMC > LMC/A (córtex cingulado anterior e o giro frontal superior e médio direito) / B-) Efeito BOLD, valores referentes da média do grupo / C -) Gráfico Boxplot do efeito BOLD médio na região de córtex cingulado anterior e giro frontal entre grupos

A -)

\begin{tabular}{|ccccc|}
\hline Frontal & Direito & Esquerdo & Superior & 2D \\
\hline & & & \\
\hline & & & \\
\hline
\end{tabular}

B-)

\begin{tabular}{|l|c|c|c|}
\hline Variáveis & LMC & LMC/A & Valor $p$ \\
\hline Efeito & 36,17 & $-28,65$ & \multirow{2}{*}{0,001} \\
BOLD & {$[10,59 ; 81,26]$} & {$[-66,31 ;-7,54]$} & \\
\hline
\end{tabular}

Medições expressadas na mediana [intervalo Interquartil]. Valor P: comparação entre LMC e LMC/A
C-)

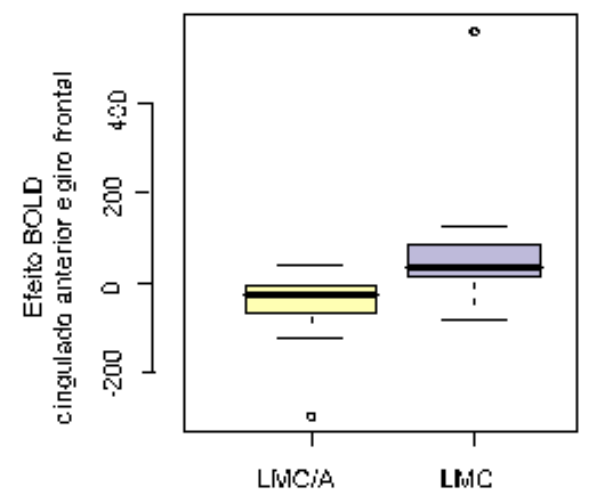

No contraste controles >LMC/A, o grupo controle apresentou maior efeito BOLD, em região do polo frontal e paracingulado, $p=0,002$ [figura 11]. 
Figura 11: A-) Imagem 3D do cérebro que contém o resultado da análise de RMf no paradigma de dor na comparação de controle> LMC/A (região do polo frontal e paracingulado) / B-) Efeito BOLD, valores referentes a média do grupo / C-) Gráfico Boxplot do efeito BOLD médio na região do polo frontal e paracingulado entre grupos

A-)

\begin{tabular}{|ccccc|}
\hline Frontal & Direito & Esquerdo & Superior & $2 \mathrm{D}$ \\
\hline (3) & & \\
\hline
\end{tabular}

B-)

\begin{tabular}{|l|c|c|c|}
\hline Variável & Controle & LMC/A & Valor $p$ \\
\hline Efeito & 6,5 & $-53,8$ & $<0,001$ \\
BOLD & {$[-14,9 ; 43,1]$} & {$[-110,4 ;-24,0]$} & \\
\hline
\end{tabular}

Medições expressadas na mediana [intervalo Interquartil]. Valor P: comparação entre controle e LMC/A
C-)

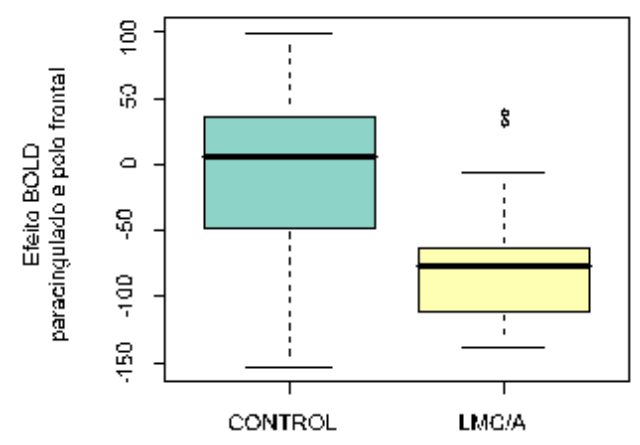

\section{2 - Teste de Atenção (Stroop)}

Os 3 grupos mostraram ativação nas áreas relacionadas à atenção durante o teste Stroop, condição incongruente> congruente. A comparação entre grupos não encontrou diferenças significativas.

Observamos diferenças significativas na velocidade de reação entre as diferentes fases do teste (fases incongruentes vs. congruentes e congruentes vs. neutras, $p<0,0001$ ). 


\section{DISCUSSÃO}

A lombalgia crônica permanece, nos dias de hoje, um importante problema de saúde. Apesar dos esforços na sua prevenção, sua prevalência continua aumentando em todo o mundo, refletindo uma compreensão ainda incompleta dos mecanismos que levam alguns indivíduos a desenvolver dor crônica. Nesse sentido, fatores biopsicossociais têm sido reconhecidos como importantes fatores de risco "yellow flags", particularmente no local de trabalho, onde o número de indivíduos afastados por causa da lombalgia é cada vez maior. Estudos mostram que a chance de o indivíduo voltar ao trabalho, depois de um afastamento, diminui de acordo com o tempo de afastamento ${ }^{10,36}$.

Postula-se que trabalhadores com LMC/A possam ser considerados um subgrupo distinto com seus próprios fatores de risco e fisiopatologia. O objetivo deste estudo foi comparar os correlatos neuronais de indivíduos LMC com e sem afastamento do trabalho. Pelo nosso conhecimento, este é o primeiro estudo que compara, através da técnica de neuroimagem funcional, estes dois grupos.

Nesta amostra, os indivíduos com LMC/A exerciam profissões comumente relacionadas a risco de lombalgia, incluindo, entre outros; motoristas de caminhão, trabalhadores da construção civil e metalurgia. Também apresentaram menor nível de educação, maior nível de ansiedade, depressão, incapacidade e medo-evitação do movimento.

Nesse sentido, estudos demonstram uma associação entre o medo do movimento relacionado à dor, medido pelo Questionário Fear-Avoidance Beliefs Questionnaire (FABQ) e a resposta ao tratamento ${ }^{37}$. Uma correlação positiva foi relatada entre os escores de FABQ e a incapacidade, dor e taxa de retorno ao 
trabalho. Sugeriu-se que as crenças de medo-evitação poderiam aumentar a percepção da dor $^{38}$. Da mesma forma, a depressão tem sido associada ao aumento do risco de cronicidade na LMC, muito embora essa relação seja considerada bidirecional ${ }^{39}$.

Por outro lado, a atenção é conhecida como um importante modulador da dor. A modulação da dor pela atenção está associada com uma ativação distinta na neuromatriz da dor ${ }^{38}$. Foi descrito que a percepção da dor diminui durante uma tarefa de atenção, paralelamente com uma redução significativa na ativação de áreas cerebrais no "circuito de atenção", incluindo córtex cingulado frontal (córtex frontal orbital e córtex cingulado anterior), matéria cinzenta periaquedutal (PAG) e tálamo posterior ${ }^{40}$.

Nosso questionamento inicial, de que a atenção poderia influenciar de forma distinta a percepção da dor em indivíduos lombálgicos com afastamento do trabalho, não foi corroborada pelos resultados do estudo. No entanto, devese enfatizar que não avaliamos a atenção específica da dor. A percepção da dor não foi controlada durante o teste Stroop. Em outras palavras, o desenho do estudo permitiu a avaliação da atenção seletiva no sentido amplo, mas não no processamento de atenção à dor.

Essa mesma situação pode ser observada em outros estudos que avaliaram a atenção e a dor, como já foi destacado por Crombez et al. ${ }^{41}$, ao declarar que métodos utilizados para investigar a atenção podem ser fundamentalmente distintos do processo de atenção para a própria dor. A atenção é considerada uma construção teórica e clínica chave para explicar a percepção da dor e a incapacidade. É provável que os indivíduos com LMC tenham mecanismos de atenção exagerados, que promovam a atividade em 
circuitos implicados na dor crônica. No entanto, pouco se sabe sobre os mecanismos neurais que auxiliam a atenção direcionada à informação nociceptiva $^{38,41}$.

Indivíduos com LMC e outras condições de dor crônica são frequentemente caracterizados como hipervigilantes ${ }^{19,42}$. O conceito de que os indivíduos são estimulados para um estado de "hipervigilância" à dor é particularmente atraente quando se avaliam clinicamente indivíduos em afastamento do trabalho frequentemente apresentando dor persistente sem uma explicação clínica-anatômica evidente. Por isso, acreditamos que essa hipótese merece maior investigação.

Em nosso estudo, a dor experimental com estímulos de igual intensidade de dor moderada, aplicada em um local neutro, provocou respostas cerebrais semelhantes nos 3 grupos de indivíduos. No entanto, houve necessidade de diferentes níveis de pressão entre os grupos do estudo, para se obter a mesma intensidade de dor. Esta mesma observação foi reportada por Giesecke et al. ${ }^{19}$, ao comparar indivíduos com LMC, fibromiálgicos e assintomáticos

Por esse motivo, realizamos uma análise covariável, considerando a pressão que foi aplicada no teste. Nesta análise, verificamos um maior efeito BOLD no córtex cingulado anterior e no giro frontal superior e médio no grupo LMC em comparação com LMC/A. O giro frontal superior (GFS) inclui o córtex premotor e o motor suplementar, os campos oculares frontais (associados ao controle do movimento ocular) córtex pré-frontal dorsolateral (associado à lógica e cálculos) e ao córtex pré-frontal (relacionado ao planejamento, pensamentos de tomada de decisão, atenção e memória funcional) ${ }^{43}$. 
Da mesma forma, no grupo controle, observou-se um maior efeito BOLD em região do polo frontal e paracingulado, em comparação com o grupo LMC/A. O polo frontal está envolvido no processamento da memória e o paracingulado no monitoramento desse processamento. Assim sendo, as diferenças observadas de ativação do polo frontal e paracingulado merecem atenção. Em um estudo recente, a atenção na dor foi avaliada, quando palavras relacionadas à dor foram mostradas aos participantes do estudo. Os indivíduos com lombalgia apresentaram maior efeito BOLD que os assintomáticos no córtex operatório central, paracingulado e o polo frontal ${ }^{44}$.

A atividade cerebral relacionada à percepção subjetiva de dor crônica pode ser distinta da atividade cerebral relacionada à dor aguda. Hashimi et al. ${ }^{45}$, avaliaram os padrões de atividade cerebral, com ressonância funcional, na transição da dor aguda para a dor crônica. Eles mostraram que a atividade cerebral na fase aguda foi limitada a regiões sensório-motoras, ínsulas bilaterais, tálamo, gânglios basais e córtex cingulado anterior, enquanto que no grupo de lombálgicos crônicos, a atividade foi confinada aos circuitos relacionados à emoção (córtex pré-frontal medial, amígdala e gânglios basais).

Em nosso estudo, não avaliamos a dor nas costas espontânea, mas sim, a dor aguda evocada por pressão aplicada em um local neutro. Baliki, et al. ${ }^{46}$, estudaram indivíduos com LMC, enquanto classificam sua dor espontânea e também compararam indivíduos com lombalgia e grupo assintomático para resposta à dor causada por estimulação térmica. Os autores descreveram uma dupla dissociação entre a atividade do córtex pré-frontal medial (CPFm, conhecido por estar envolvido em emoções negativas especialmente em relação ao eu) e ínsula. Enquanto a atividade do cérebro no CPFm correlacionou-se com 
a intensidade da dor espontânea, as regiões cerebrais comumente observadas para a dor aguda correlacionaram-se com a estimulação térmica.

Uma revisão sistemática recente analisou a literatura disponível sobre anormalidades cerebrais estruturais e funcionais na dor lombar crônica, avaliada por várias técnicas de imagem de ressonância magnética cerebral. Seis estudos avaliaram a atividade cerebral em resposta a um estímulo nociceptivo, três deles com estimulação mecânica. Em geral, esses estudos revelaram algumas evidências de aumento da atividade em regiões relacionadas à dor e diminuição da atividade em regiões analgésicas ${ }^{47}$.

Em contraste com esses dados, não observamos nenhuma distinção na atividade cerebral entre os três grupos de indivíduos em áreas relacionadas à dor aguda. Curiosamente, encontramos um efeito BOLD reduzido em áreas cerebrais relacionadas à emoção no grupo LMC/A em comparação com LMC e controle. Nossa hipótese post-hoc é que essas áreas já poderiam estar ativadas em indivíduos com afastamento do trabalho. As emoções negativas estão associadas ao aumento da ativação no córtex cingulado anterior e outras áreas que medeiam o processamento das emoções importantes para sinalizar a atenção na dor ${ }^{38}$. São necessários mais estudos para abordar esta questão.

Nosso estudo corrobora o conceito de que a presença de dor crônica está associada a uma alteração na plasticidade neuronal em áreas cerebrais que se estendem além das regiões somatossensíveis para incluir áreas que processam as emoções. 


\section{CONCLUSÃO}

$\mathrm{Na}$ comparação dos correlatos neuronais entre indivíduos com LMC/A, LMC e controles, não encontramos diferença nas ativações de RMf, após um teste de atenção. Porém, observamos um estado de hiperalgesia em indivíduos com LMC, demonstrada por menor pressão para se obter a mesma intensidade de dor e efeito BOLD. Também observamos uma modulação gradual da dor aguda no giro cingulado anterior e giro frontal, sendo que os indivíduos com LMC/A apresentaram um menor efeito BOLD em relação aos indivíduos com LMC e estes um menor efeito BOLD nas mesmas áreas quando comparados com controle. 


\section{REFERÊNCIAS}

1 - Krismer M, van Tulder M; Low Back Pain Group of the Bone and Joint Health Strategies for Europe Project. Strategies for prevention and management of musculoskeletal conditions. Low back pain (non-specific). Best Pract Res ClinRheumatol. 2007;21(1):77-91.

2 - Manchikanti L, Singh V, Falco FJ, et al. Epidemiology of low back pain in adults. Neuromodulation 2014;17(Suppl 2):3-10.

3 - Balagué F, Mannion AF, Pellisé F, et al. Non-specific low back pain. Lancet 2012;379(9814):482-91.

4 - Pincus T, Santos R, Breen A. et al. A Review and Proposal for a Core Set of Factors for Prospective Cohorts in Low Back Pain: A Consensus Statement. Arthritis\&Rheumatism 2008 Jan 15; 59(1):14-24.

5 - Ramond A, Bouton C, Richard I, et al. Psychosocial risk factors for chronic low back pain in primary care a systematic review. Fam Pract 2011;28(1):12-21.

6 - Cancelliere C, Donovan J, Stochkendahl MJ, et al. Factors affecting return to work after injury or illness: best evidence synthesis of systematic reviews. Chiropractic \& Manual Therapies 2016;24(1):32.

7 - Hoy D, Brooks P, Blyth F, et al. The Epidemiology of low back pain. Best Pract Res Clin Rheumatol 2010;24(6):769-81.

8 - Shmagel A, Foley R, Ibrahim H. Epidemiology of Chronic Low Back Pain in US Adults: Data From the 2009-2010 National Health and Nutrition Examination Survey. Arthritis Care Res (Hoboken) 2016;68(11):1688-1694.

9 - Waddel G. A new Clinical Model for the treatment of Low Back Pain. Spine 1987;12(7):632-44.

10 - Ivo R, Nicklas A, Dargel J. Brain structural and psychometric alterations in chronic low back pain. Eur Spine J 2013;22(9):1958-64. 
11 - Salvetti MG, Pimenta CA, Braga PE, et al. Disability related to chronic low back pain: prevalence and associated factors. Rev Esc Enferm USP 2012;46:1623.

12 - Meziat FN, Silva GA. Disability pension from back pain among social security beneficiaries, Brazil. Rev Saude Publica. 2011;45:494-502.

13 - http://www.brasil.gov.br/economia-e-emprego/2017/04/dor-nas-costas-e-amaior-causa-de-afastamento-do-trabalho

14 - Tracey I. Imaging pain. Br J Anaesth. 2008;101(1):32-9.

15 - Amaro E Jr, Barker GJ. Study design in fMRI: basic principles. Brain Cogn 2006 Apr;60(3):220-32.

16 - Ogawa S, Lee TM, Kay AR, et al. Brain magnetic resonance imaging with contrast depend on blood oxygenation. Proc Natl Acad Sci U S A 1990;87(24):9868-72.

17 - Geha P, Waxman SG. Pain Perception: Multiple Matrices or One? JAMA Neurol. 2016;73(6):628-30.

18 - Apkarian AV. The brain in chronic pain: clinical implications. Pain management. 2011;1(6):577-586.

19 - Giesecke T, Gracely RH, Grant MA, et al. Evidence of augmented central pain processing in idiopathic chronic low back pain. Arthritis Rheum. 2004;50(2):613-23.

20 - Davis KD. Neuroimaging of pain: what does it tell us? Curr Opin Support Palliart Care. 2011;5(2):116-21.

21- Martinsen S, Flodin P, Berrebi J, et al. Fibromyalgia Patients Had Normal Distraction Related Pain Inhibition but Cognitive Impairment Reflected in Caudate Nucleus and Hippocampus during the Stroop Color Word Test. PLoS One 2014;9(10):e108637.

22 - Jensen AR, Rohwer WD Jr. The Stroop color-word test: a review. Acta Psychol (Amst) 1966;25(1):36-93. 
23 - Walteros C, Sánchez-Navarro JP, Muñoz MA, et al. Altered associative learning and emotional decision making in fibromyalgia. J Psychosom Res 2011;70(3):294-301.

24 - Abeare CA, Cohen JL, Axelrod BN, et al. Pain, executive functioning, and affect in patients with rheumatoid arthritis. Clin J Pain 2010;26(8):683-9.

25 - Thirion B, Pinel P, Mériaux S, et al. Analysis of a large fMRI cohort: Statistical and methodological issues for group analyses. Neuroimage. 2007;35(1):105-20.

26 - Nusbaum L, Natour J, Ferraz MB, et al. Translation, adaptation and validation of the Roland-Morris questionnaire - Brazil Roland Morris. Brazilian Journal of Medical and Biological Research; 2001;34(2):203-10.

27 - Gracely RH, Geisser ME, Giesecke T, et al. Pain catastrophizing and neural responses to pain among persons with fibromyalgia. Brain. 2004;127:835-43.

28 - www.abep.org/Servicos/Download.aspx?id=07

29 - Beck AT, Ward CH, Mendelson M, et al. An inventory for measuring depression. Arch Gen Psychiatry 1961:561-71.

30 - Fioravanti ACM, Santos FS, Maissonette S, et al. Avaliação da estrutura fatorial da Escala de Ansiedade-Traço do IDATE. Avaliação Psicológica 2006;5(2):217-224.

31 - Abreu AM, Faria CDCM, Cardoso SMV, et al. Versão brasileira do Fear Avoidance Beliefs Questionnaire. Cad. Saúde Pública, 2008;24(3):615-23.

32 - Woolrich MW, Ripley BD, Brady M, et al. Temporal autocorrelation in univariate linear modeling of FMRI data. Neuroimage. 2001;14(6):1370-86.

33 - Faraway JJ. Extending the linear model with R: generalized linear, mixed effects and nonparametric regression models. Boca Raton: Chapman \& Hall/CRC, 2006.

34 - SPSS Inc. Released 2008. SPSS Statistics for Windows, Version 17.0. Chicago: SPSS Inc. 
35 - R Core Team (2015). R: A language and environment for statistical computing. R Foundation for Statistical Computing, Vienna, Austria. URL http://www.R-project.org/

36 - Maher C, Underwood M, Buchbinder R. Non-specific low back pain. Lancet 2017 18;389:736-47.

37 - Feitosa AS, Lopes JB, Bonfa E, et al. A prospective study predicting the outcome of chronic low back pain and physical therapy: the role of fear-avoidance beliefs and extraspinal pain. Rev Bras Reumatol. 2016;56(5):384-90.

38 - Garland EL. Pain processing in the human nervous system: a selective review of nociceptive and biobehavioral pathways. Prim Care. 2012;39(3):56171.

39 - Fernandez M, Colodro-Conde L, Hartvigsen J, et al. Chronic low back pain and the risk of depression or anxiety symptoms: Insights from a longitudinal twin study. Spine J. 2017;17(7):905-912.

40 - Valet M, Sprenger T, Boecker H, et al. Distraction modulates connectivity of the cingulo-frontal cortex and the midbrain during pain-an fMRI analysis. Pain. 2004;109(3):399-408.

41 - Crombez, G, Heathcote LC, Fox E. The puzzle of attentional bias to pain: beyond attention. Pain. 2015;156(9):1581-2.

42 - Crombez G, Van Damme S, Eccleston C. Hypervigilance to pain: an experimental and clinical analysis. Pain. 2005;116(1-2):4-7. Review.

43 - Vernet M, Quentin R, Chanes L, et. al. Frontal eye field, where art thou? Anatomy, function, and non-invasive manipulation of frontal regions involved in eye movements and associated cognitive operations. Frontiers in Integrative Neuroscience. 2014;8:66.

44 - Taylor AM, Harris AD, Varnava A, et al. Neural responses to a modified Stroop paradigm in patients with complex chronic musculoskeletal pain compared to matched controls: an experimental functional magnetic resonance imaging study. BMC Psychol. 2016;4:5. 
45 -Hashmi JA, Baliki MN, Huang L, et al. Shape shifting pain: chronification of back pain shifts brain representation from nociceptive to emotional circuits. Brain. 2013;136(9):2751-68.

46 - Baliki MN, Chialvo DR, Geha PY, et al. Chronic pain and the emotional brain: specific brain activity associated with spontaneous fluctuations of intensity of chronic back pain. J Neurosci. 2006;26(47):12165-73.

47 - Kregel J, Meeus M, Malfliet A, et al. Structural and functional brain abnormalities in chronic low back pain: A systematic review. Semin Arthritis Rheum. 2015;45(2):229-37. 


\section{ANEXO}

\section{1 -Termo de Consentimento Livre e Esclarecido - v. 1 17/07/2010:}

\section{Ressonância Magnética Funcional em pacientes de lombalgia crônica}

Esta pesquisa visa estudar, através de imagens funcionais do cérebro, pessoas saudáveis e pessoas com dor de coluna, enquanto realizam atividades mentais e durante estímulos de sensibilidade da pele e de dor de intensidade baixa e moderada.

Você responderá a alguns questionários, e no dia do exame ficará no interior do aparelho de ressonância magnética, que é semelhante a um pequeno túnel. Você será informado e treinará a realização dos testes antes de entrar no equipamento. Durante todo o procedimento você será observado (a) pela equipe. Poderá se comunicar através de um microfone e ouvir o médico através de um fone de ouvido (que também serve para reduzir o ruído produzido pelo aparelho). Algumas pessoas não se sentem à vontade quando entram no aparelho de ressonância magnética, já que é um lugar fechado. Caso você decida, poderá ser retirado do aparelho a qualquer momento.

Enquanto estiver dentro do aparelho de ressonância magnética você realizará algumas atividades que envolvem apertar botões de acordo com instruções mostradas em uma tela. Numa das fases do exame você receberá estímulos dolorosos na pele. É você que irá determinar a intensidade máxima suportável da dor, e poderá interromper o experimento se julgar necessário. Durante esta fase você deverá informar o nível (grau) de dor após cada estímulo que sentir.

O principal benefício desta pesquisa é entender melhor como a percepção de dor acontece do ponto de vista de ativação cerebral. É possível que com este conhecimento seja possível desenvolver mecanismos para melhorar o diagnóstico de pessoas com dor lombar, e assim tornar mais precisa a indicação de diferentes tipos de tratamentos. Entretanto, esta pesquisa atual não traz nenhum benefício direto para sua saúde.

Não há outros métodos utilizados para detectar atividade cerebral que produzam a mesma informação, sem utilização de substância radioativa.

A qualquer momento desta pesquisa você poderá contatar o pesquisador nos números abaixo, para esclarecimentos sobre o curso da pesquisa.

A qualquer momento você poderá se recusar a participar ou retirar seu consentimento, sem penalização alguma e sem prejuízo ao seu cuidado neste Hospital.

As informações que possam identificá-lo serão retiradas, e codificadas de maneira a assegurar a garantia do sigilo e privacidade quanto aos dados confidenciais envolvidos nesta pesquisa.

Não haverá despesas na sua participação, portanto não estão previstos ressarcimentos (item IV da Res. 196/96).

Apesar do exame não ter fins diagnósticos (ele não é completo para isto), às vezes mostra alterações inesperadas em pessoa sadia. Se isto ocorrer, será discutido com o (a) Sr. (a), e você receberá as orientações necessárias conforme o achado.

Em caso de dúvida relacionada a esta pesquisa, você poderá entrar em contato com Dra Liliana L Jorge tel 988130085, Aloma Feitosa tel0994739603, ou Juliana Molina tel 980665140

Lí e estou de acordo com os termos acima,

São Paulo, de de 201_

Voluntário:

Assinatura:

Pesquisador:

Assinatura: 


\section{2 - Comitê de Ética do Hospital das Clinicas da FMUSP (CAPPesq 0186/11)}

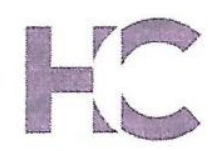

\section{APROVAÇÃO}

A Comissão de Ética para Análise de Projetos de Pesquisa CAPPesq da Diretoria Clínica do Hospital das Clínicas da Faculdade de Medicina da Universidade de São Paulo, em sessão de 20/04/2011, APROVOU o Protocolo de Pesquisa $n^{\circ}$ 0186/11, intitulado: "RESSONÂNCIA MAGNÉtICA FUNCIONAL EM PORTADORES DE LOMBALGIA CRÔNICA COM REIVINDICAÇÖES TRABALHISTAS", apresentado pelo Departamento de CLínICA MÉDICA, inclusive o Termo de Consentimento Livre e Esclarecido.

Cabe ao pesquisador elaborar e apresentar à CAPPesq, os relatórios parciais e final sobre a pesquisa (Resolução do Conselho Nacional de Saúde n० 196, de 10/10/1996, inciso IX.2, letra "c").

Pesquisador (a) Responsável: Ari Stiel Radu Halpern

CAPPesq, 20 de Abril de 2011

PROF. DR. EUCLIDES AYRES DE CASTILHO

Coordenador

Comissão de Ética para Análise de

Projetos de Pesquisa - CAPPesq

\footnotetext{
Comissão de Ética para Análise de Projetos de Pesquisa do HCFMUSP da Diretoria Clinica do Hospital das Clinicas da Faculdade de Medicina da Universidade de São Paulo Rua Ovidio Pires de Campos, 225, $5^{\circ}$ andar - CEP 05403010 - São Paulo - SP Fone: 01130696442 Fax: 01130696492 e-mail: cappesq@hcnet.usp.br
} 


\author{
Hospital das Clínicas da FMUSP \\ Comissão de Ética para Análise de Projetos de Pesquisa \\ CAPPesq
}

No Protocolo: 0186/11

Tílulo: RESSONÂNCIA MAGNÉICA FUNCIONAL EM PORTADORES DE LOMBALGIA CRÔNICA COM REIVINDICAÇÕES TRABALHISTAS

Pesquisador Responsável: Ari Stiel Radu Halpem

Pesquisador Executanie: $O$ Mesmo

Depariamento: CLÍNICA MÉDICA

- Coordenadior ca Comissço de Éfica para Análise de Projelos de Pesquisa - CAPPesq da Diretoria Clínica do Hospital das Clínicas da Faculdade de Medicina da Universidade de São Paulo, APROVOu / TOMOU ClÊNCIA adreferendum em 08/10/2013, do[s] documento[s] abcixo mencionado(s):

- Carta datada de 04/10/13 - Inclusão da aluna Aloma da Silva Alvares Feîlosa

A CAPPesq em obediência à Resolução CNS 466/12, solicita ao pesquisador (a) s elaboração de relatório parcial e final.

No caso de relatório parcial é necessário informar o tempo previsto para a conclusão do protocolo e breve resumo dos resultados obtidos.

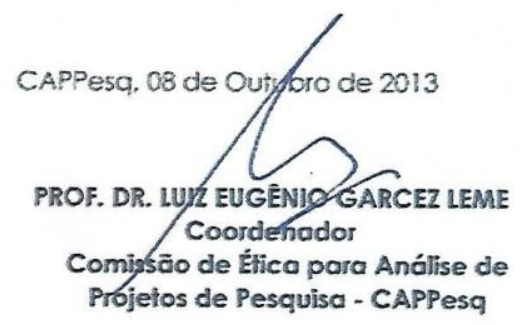

Pus Dr. Ovidio Pires de Campas, 225 - Prédio da Administraçāo - $5^{\circ}$ andar - CEP 05403.010 - Sâo Paulo - SP $55112661-7585-55112661-6442$ ramais: $16,17,18$ ! marcia. carvatho@ hc.tm.usp.br 


\section{3 - Comitê de Ética do Hospital Albert Einstein (CEP/Einstein no10/1480)}

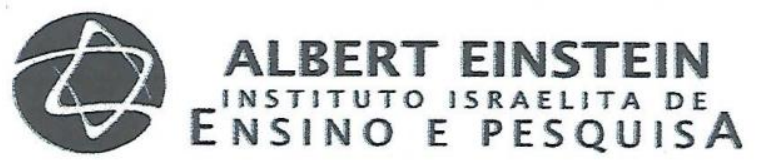

Säo Paulo, 15 de dezembro de 2010.

Processo CEP/Einstein $n^{\circ} 1011480$

Projeto de Grupo III

Título: "Ressonância magnética funcional em portadores de lombalgia crônica com reinvidicaçōes trabalhistas." E-NOBORl. Protocolo versão 2 de 4 de novembro de 2010, Termo de Consentimento Livre $\&$ Esclarecido versão 1 de 17 de julho de 2010

Pesquisador responsável: Ari Stiel Radu

Instituição proponente: Departamento de Imagem/HIAE

Instituiçäo co-participante: Hospital das Clinicas da Faculdade de Medicina da USP

Entrada no CEPIEinstein: 8 de dezembro de 2010.

Patrocinador: pesquisador

\section{PARECER}

O Comitê de Ética em Pesquisa do Hospital Israelita Albert Einstein no cumprimento de suas atribuiçōes, analisou e aprovou o projeto de pesquisa supracitado, bem como o Termo de Consentimento Livre e Esclarecido.

Aproveitamos a oportunidade para orientar o pesquisador sobre os seguintes itens:

- O sujeito da pesquisa tem a liberdade de recusar-se a participar ou de retirar seu consentimento em qualquer fase da pesquisa, sem penalização alguma e sem prejuizo ao seu cuidado (Res. CNS 196/96 ltem (V.1.f) e deve receber uma cópia do Termo de Consentimento Livre Esclarecido, na integra, por ele assinado (ltem IV.2d).

- O pesquisador deve desenvolver a pesquisa conforme delineada no protocolo aprovado e descontinuar o estudo somente após análise das razōes da descontinuidade pelo CEP que o aprovou (Res. CNS 196 ltem III. 3z), aguardando seu parecer, exceto quando perceber risco ou dano näo previsto ao sujeito participante ou quando constatar a superioridade de regime oferecido a um dos grupos da pesquisa (ltern V.3) que requeiram ação imediata. 


\section{ALBERT EINSTEIN

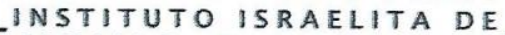 ENSINO E PESQUISA}

- O CEP deve ser informado de todos os efeitos adversos ou fatos relevantes que alterem o curso normal do estudo (Res. CNS Item V.4). É papel do pesquisador, assegurar medidas imediatas adequadas frente a evento adverso grave ocorrido (mesmo que tenha sido em outro Ocentro) e enviar notificaçâo ao CEP e à Agência Nacional de Vigilância Sanitária - ANVISA - junto com seu posicionamento.

- Eventuais modificaçöes ou emendas ao protocolo devem ser apresentadas ao CEP de forma clara e sucinta, identificando a parte do protocolo a ser modificada e suas justificativas.

- Ao pesquisador cabe elaborar e apresentar ao CEPIEinstein os relatórios semestrais e o relatório final (Res. CNS 196, X.2.c), inicialmente em 15 de junho de 2011, conforme o modelo padronizado disponivel em http:llapps.einstein.briforms/pesquisa/form-padr.html

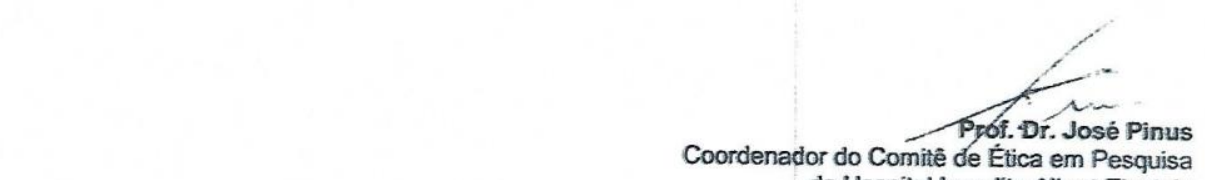
do Hospital Israelita Albert Einstein

Institutto de Ensino e Pesguisa do Hospital Israelita Albert Einstein

Av. Albert Einstein, 627 - Morumbi - Säo Paulo - SP - 05651901 - Brasil

Tel: $(55-11) 21513729$ Fax: $(55-11) 21510273$

Internet: www. einstein.br 
MiNisTÉRIO dA SAÚdE

TERIO DA SAUDE

Comissåo Nacional de Ética em Pesquisa - CONEP

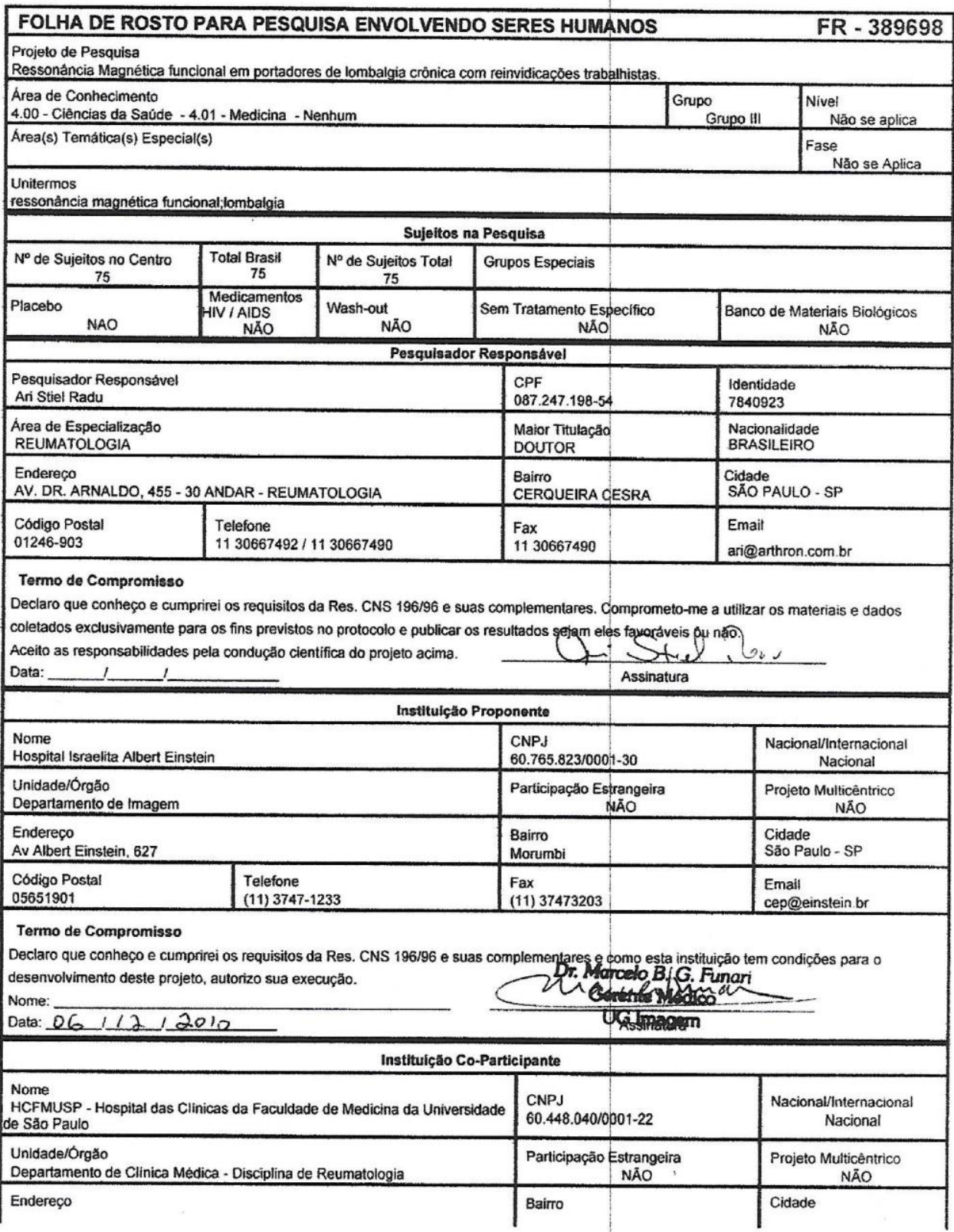


São Paulo, 06 de agosto de 2013

CEP $10 / 1480$

CAAE: $0212 \cdot 0.028 .015-10$

Titulo: Ressonância Magnética Funcional em portadores de lombalgia crônica com reivindicações trabalhistas.

Investigador Principal: Dr. Ari Stiel Radu Halpern

Ilmo. Sr.

Dr. Ari Stiel Radu Halpern

O Comitê de Ética em Pesquisa do Hospital Israelita Albert Einstein analisou e aprovou a inclusão da pesquisadora Aloma da Silva Alvares Feitosa, como membro de equipe do projeto supracitado.

Atenciosamente,

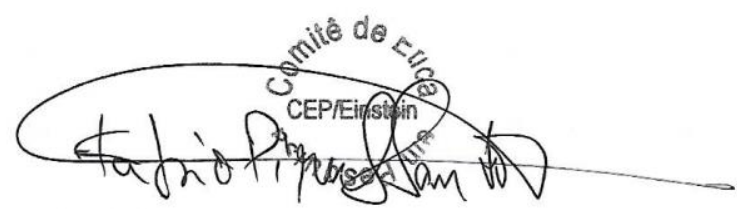

Dr. Fabio Pires de Souza Santos

Coordenador do Comitê de Ética em Pesquisa do Hospital Israelita Albert Einstein 


\section{4 - QUESTIONÁRIO DE INCAPACIDADE ROLAND-MORRIS - QIRM (Roland}

\section{e Morris, 1983. Versão Modificada Sarda e col. 2010)}

Nome:

Data:

Quando você tem dor, você pode ter dificuldade em fazer algumas coisas que normalmente faz. Esta lista possui algumas frases que as pessoas usam para se descreverem quando tem dor. Quando você ler estas frases poderá notar que algumas descrevem sua condição atual. Ao ler ou ouvir estas frases pense em você hoje. Assinale com $x$ apenas as frases que descrevem sua situação hoje, se a frase não descrever sua situação deixe-a em branco e siga para a próxima sentença. Lembre-se assinale apenas a frase que você tiver certeza que descreve você hoje.

1. Fico em casa a maior parte do tempo por causa da minha dor

2. Mudo de posição frequentemente tentando ficar mais confortável com a dor.

3. Ando mais devagar que o habitual por causa da dor.

4. Por causa da dor eu não estou fazendo alguns dos trabalhos que geralmente faço em casa.

5. Por causa da dor eu uso o corrimão para subir escadas.

6. Por causa da dor eu deito para descansar mais frequentemente.

7. Por causa da dor eu tenho que me apoiar em alguma coisa para me levantar de uma poltrona

8. Por causa da dor tento com que outras pessoas façam as coisas para mim

9. Eu me visto mais devagar do que o habitual por causa das minhas dores.

10. Eu somente fico em pé por pouco tempo por causa da dor.

12. Tenho dificuldade em me levantar de uma cadeira por causa da dor.

11. Por causa da dor tento não me abaixar ou me ajoelhar.

13. Sinto dor quase todo o tempo.

14. Tenho dificuldade em me virar na cama por causa da dor.

15. Meu apetite não é muito bom por causa das minhas dores.

16. Tenho dificuldade para colocar minhas meias por causa da dor.

17. Caminho apenas curtas distâncias por causa das minhas dores.

18. Não durmo tão bem por causa das dores.

19. Por causa da dor me visto com ajuda de outras pessoas

20. Fico sentado a maior parte do dia por causa da minha dor 22. Por causa da dor estou mais irritado e mal-humorado com as pessoas do que em geral

21. Evito trabalhos pesados em casa por causa da minha dor.

23. Por causa da dor subo escadas mais vagarosamente do que o habitual.

24. Fico na cama (deitado ou sentado) a maior parte do tempo por causa das minhas dores. 


\section{5 - CLASSIFICAÇÃO SÓCIO ECONÔMICA \\ Critério ABA-ABIPEME}

Nome:

\section{A-) Instrução do chefe da família}

- analfabeto/primário incompleto

- primário completo/ginasial incompleto

- ginasial completo/colegial incompleto

- colegial completo/superior incompleto

- superior completo

B) Itens de conforto familiar

\begin{tabular}{|c|c|c|c|c|c|c|c|}
\hline \multirow[t]{2}{*}{ Ítens de posse } & \multirow[t]{2}{*}{ Não tem } & \multicolumn{6}{|c|}{ Quantidade possuída } \\
\hline & & 1 & 2 & 3 & 4 & 5 & $6 e+$ \\
\hline Automóvel & & & & & & & \\
\hline televisor em cores & & & & & & & \\
\hline rádio (excluindo o do carro) & & & & & & & \\
\hline Banheiro & & & & & & & \\
\hline empregada mensalista & & & & & & & \\
\hline aspirador de pó & & & & & & & \\
\hline máquina de lavar roupa & & & & & & & \\
\hline vídeo cassete & & & & & & & \\
\hline geladeira comum ou $\mathrm{c} /$ free & & & & & & & \\
\hline
\end{tabular}




\section{6 - ESCALA BECK DE DEPRESSÃO}

Nome:.

Data.

Neste questionário existem grupos de afirmativas. Por favor, leia cada uma delas e selecione a afirmativa que melhor descreva como você se sentiu NA SEMANA QUE SE PASSOU, INCLUINDO O DIA DE HOJE. Desenhe um círculo ao lado da afirmativa que tiver selecionado. Se várias afirmativas no grupo parecem aplicar-se igualmente bem, circule cada uma delas. Certifique-se de ter lido todas as afirmativas de cada item antes de fazer sua escolha.

1. 0 Não me sinto triste.

1 Sinto-me triste.

2 Sinto-me triste o tempo todo e não consigo sair disso.

3 Estou tão triste e infeliz que não posso aguentar.

2. 0 Não estou particularmente desencorajado (a) quanto ao futuro.

1 Sinto-me desencorajado (a) quanto ao futuro.

2 Sinto que não tenho nada por esperar.

3 Sinto que o futuro é sem esperança e que as coisas não podem melhorar.

3. 0 Não me sinto fracassado (a).

1 Sinto que falhei mais que o indivíduo médio.

2 Quando olho para traz em minha vida, tudo que vejo é um porção de fracassos.

3 Sinto que sou um fracasso completo como pessoa.

4. O Obtenho tanta satisfação com as coisas como costumava fazer.

1 Não gosto das coisas como costumava gostar.

2 Não consigo sentir mais satisfação real com coisa alguma.

3 Estou insatisfeito (a) ou entediado (a) com tudo.

5. 0 Não me sinto particularmente culpado (a).

1 Sinto-me culpado (a) boa parte do tempo.

2 Sinto-me culpado (a) a maior parte do tempo.

3 Sinto-me culpado (a) o tempo todo.

6. 0 Não sinto que esteja sendo punido (a).

1 Sinto que posso ser punido (a).

2 Sinto que estou sendo punido (a). 
7. 0 Não me sinto desapontado (a) comigo mesmo (a).

1 Sinto-me desapontado (a) comigo mesmo (a).

2 Sinto-me aborrecido (a) comigo mesmo(a).

3 Eu me odeio.

8. 0 Não sinto que eu seja pior que qualquer outra pessoa.

1 Critico minhas fraquezas ou erros.

2 Responsabilizo-me o tempo todo por minhas falhas.

3 Culpo-me por todas as coisas ruins que me acontecem.

9. 0 Não tenho nenhum pensamento a respeito de matar.

1 Tenho pensamentos a respeito de me matar mas não os levaria adiante.

2 Gostaria de matar.

3 Eu me mataria se tivesse uma oportunidade.

10. 0 Não costumo chorar mais que o habitual.

1 Choro agora mais que costumava fazer.

2 Atualmente choro o tempo todo.

3 Eu costumava conseguir chorar, mas agora não consigo, mesmo que queira.

11. 0 Não me irrito mais agora do que qualquer outra época.

1 Fico molestado (a) ou irritado (a) mais facilmente do que costumava.

2 Atualmente sinto-me irritado (a) todo tempo.

3 Absolutamente não me irrito com as coisas que costumavam irritar-me.

12. 0 Não perdi o interesse nas outras pessoas.

1 Interesso-me menos do que costumava pelas outras pessoas.

2 Perdi a maior parte do meu interesse nas outras pessoas.

3 Perdi todo o meu interesse nas outras pessoas.

13. 0 Tomo decisões mais ou menos tão bem como em qualquer outra época.

1 Adio minhas decisões mais do que costumava.

2 Tenho maior dificuldade em tomar decisões mais do que antes.

3 Não consigo mais tomar decisões.

14. 0 Não sinto que minha aparência seja pior do que costumava ser.

1 Preocupo-me por estar parecendo velho (a) ou sem atrativos.

2 Sinto que há mudanças permanentes em minha vida que me fazer parecer sem atrativos.

3 Considero-me feio (a). 
15. 0 Posso trabalhar mais ou menos tão bem como antes.

1 Preciso de um esforço extra para começar qualquer coisa.

2 Tenho que me forçar muito até fazer qualquer coisa.

3 Não consigo fazer nenhum trabalho.

16. 0 Durmo tão bem quanto de hábito.

1 Não durmo tão bem quanto costumava.

2 Acordo 1 ou 2 horas mais cedo do que de hábito e tenho dificuldade de voltar a dormir.

3 Acordo várias horas mais cedo do que costumava e tenho dificuldades de voltar a dormir.

17. 0 Não fico mais cansado (a) do que o hábito.

1 Fico cansado (a) com mais facilidade do que costumava.

2 Sinto-me cansado (a) ao fazer quase qualquer coisa.

3 Estou cansado(a) demais para fazer qualquer coisa.

18. 0 Meu apetite não está pior do que o de hábito.

1 Meu apetite não é tão bom quanto costumava ser.

2 Meu apetite está muito pior agora.

3 Não tenho mais nenhum apetite.

19. 0 Não perdi muito peso se é que perdi algum ultimamente.

1 Perdi mais de $2,5 \mathrm{~kg}$.

2 Perdi mais de $5,0 \mathrm{~kg}$.

3 Perdi mais de $7,5 \mathrm{~kg}$.

Estou deliberadamente tentando perder peso, comendo menos - sim ( ) não ( )

20. 0 Não me preocupo mais que de hábito com minha saúde.

1 Preocupo-me com problemas físicos, como dores e aflições, ou perturbações no estômago ou prisões de ventre.

2 Estou muito preocupado (a) com problemas físicos e é difícil pensas em muito mais que isso.

3 Estou tão preocupado (a) com meus problemas físicos que não consigo pensar em outra coisa.

21. 0 Não tenho observado qualquer mudança recente em meu interesse sexual.

1 Estou menos interessado (a) por sexo do que costumava.

2 Estou bem menos interessado (a) em sexo atualmente.

3 Perdi completamente o interesse por sexo. 


\section{7 - Inventário de Ansiedade Traço-Estado - IDATE-T}

Leia cada pergunta e faça um círculo ao redor do número à direita que melhor indicar como você geralmente se sente. Não gaste muito tempo numa única afirmação, mas tente dar a resposta que mais se aproximar de como você se sente geralmente.

Avaliação

Quase nunca..1 Às vezes...2 Freqüentemente...3 Quase sempre....4

\begin{tabular}{|c|c|c|c|c|c|}
\hline Item & Descrição & & & & \\
\hline 1 & Sinto-me bem & 1 & 2 & 3 & 4 \\
\hline 2 & Canso-me facilmente & 1 & 2 & 3 & 4 \\
\hline 3 & Tenho vontade de chorar & 1 & 2 & 3 & 4 \\
\hline 4 & Gostaria de ser tão feliz quanto os outros parecem ser & 1 & 2 & 3 & 4 \\
\hline 5 & $\begin{array}{l}\text { Perco oportunidades porque não consigo tomar decisões } \\
\text { rápidas }\end{array}$ & 1 & 2 & 3 & 4 \\
\hline 6 & Sinto-me descansado & 1 & 2 & 3 & 4 \\
\hline 7 & Sinto-me calmo, ponderado e senhor de mim mesmo & 1 & 2 & 3 & 4 \\
\hline 8 & $\begin{array}{l}\text { Sinto que as dificuldades estão se acumulando de tal forma } \\
\text { que não as consigo resolver }\end{array}$ & 1 & 2 & 3 & 4 \\
\hline 9 & Preocupo-me demais com as coisas sem importância & 1 & 2 & 3 & 4 \\
\hline 10 & Sou feliz & 1 & 2 & 3 & 4 \\
\hline 11 & Deixo-me afetar muito pelas coisas & 1 & 2 & 3 & 4 \\
\hline 12 & Não tenho confiança em mim mesmo & 1 & 2 & 3 & 4 \\
\hline 13 & Sinto-me seguro & 1 & 2 & 3 & 4 \\
\hline 14 & Evito ter que enfrentar crises e problemas & 1 & 2 & 3 & 4 \\
\hline 15 & Sinto-me deprimido & 1 & 2 & 3 & 4 \\
\hline 16 & Estou satisfeito & 1 & 2 & 3 & 4 \\
\hline 17 & $\begin{array}{l}\text { Às vezes idéias sem importância me entram na cabeça e } \\
\text { ficam me preocupando }\end{array}$ & 1 & 2 & 3 & 4 \\
\hline 18 & $\begin{array}{l}\text { Levo os desapontamentos tão a sério que não consigo tirá- } \\
\text { los da cabeça }\end{array}$ & 1 & 2 & 3 & 4 \\
\hline 19 & Sou uma pessoa estável & 1 & 2 & 3 & 4 \\
\hline 20 & $\begin{array}{l}\text { Fico tenso e perturbado quando penso em meus problemas } \\
\text { do momento }\end{array}$ & 1 & 2 & 3 & 4 \\
\hline
\end{tabular}




\section{8 - Inventário de Ansiedade Traço-Estado - IDATE-E}

Leia cada pergunta e faça um círculo em redor do número à direita que melhor indicar como você se sente agora, neste momento. Não gaste muito tempo numa única afirmação, mas tente dar a resposta que mais se aproxime de como você se sente neste momento.

\section{Avaliação}
Absolutamente não..1
Um pouco.....2
Bastante....3
Muitíssimo....4

\begin{tabular}{clllll}
\hline Item & \multicolumn{1}{c}{ Descrição } & & & \\
\hline $\mathbf{1}$ & Sinto-me calmo(a) & 1 & 2 & 3 & 4 \\
$\mathbf{2}$ & Sinto-me seguro(a) & 1 & 2 & 3 & 4 \\
$\mathbf{3}$ & Estou tenso(a) & 1 & 2 & 3 & 4 \\
$\mathbf{4}$ & Estou arrependido(a) & 1 & 2 & 3 & 4 \\
$\mathbf{5}$ & Sinto-me à vontade & 1 & 2 & 3 & 4 \\
$\mathbf{6}$ & Sinto-me perturbado(a) & 1 & 2 & 3 & 4 \\
$\mathbf{7}$ & Estou preocupado(a) com possíveis infortúnios & 1 & 2 & 3 & 4 \\
$\mathbf{8}$ & Sinto-me descansado(a) & 1 & 2 & 3 & 4 \\
$\mathbf{9}$ & Sinto-me ansioso(a) & 1 & 2 & 3 & 4 \\
$\mathbf{1 0}$ & Sinto-me "em casa" & 1 & 2 & 3 & 4 \\
$\mathbf{1 1}$ & Sinto-me confiante & 1 & 2 & 3 & 4 \\
$\mathbf{1 2}$ & Sinto-me nervoso(a) & 1 & 2 & 3 & 4 \\
$\mathbf{1 3}$ & Estou agitado(a) & 1 & 2 & 3 & 4 \\
$\mathbf{1 4}$ & Sinto-me uma pilha de nervos & 1 & 2 & 3 & 4 \\
$\mathbf{1 5}$ & Estou descontraído(a) & 1 & 2 & 3 & 4 \\
$\mathbf{1 6}$ & Sinto-me satisfeito(a) & 1 & 2 & 3 & 4 \\
$\mathbf{1 7}$ & Estou preocupado(a) & 1 & 2 & 3 & 4 \\
$\mathbf{1 8}$ & Sinto-me superexcitado(a)e confuso(a) & 1 & 2 & 3 & 4 \\
$\mathbf{1 9}$ & Sinto-me alegre & 1 & 2 & 3 & 4 \\
$\mathbf{2 0}$ & Sinto-me bem & 1 & 2 & 3 & 4 \\
\hline
\end{tabular}




\section{9 - Fear Avoidance Beliefes Questionnaire- versão português do Brasil}

Para cada afirmação, circular um número de 0 a 6 , para informar quanto as atividades físicas como fletir o tronco, levantar, caminhar ou dirigir, afetam sua dor nas costas. Instruções: $0=$ discordo completamente; 1 = discordo razoavelmente; 2 = discordo ligeiramente; 3 = não sei dizer; 4 = concordo ligeiramente; 5 concordo razoavelmente; 6 = concordo completamente

\begin{tabular}{|l|l|l|l|l|l|l|l|}
\hline 1-) Minha dor foi causada por atividade física & 0 & 1 & 2 & 3 & 4 & 5 & 6 \\
\hline 2-) A atividade física faz minha dor piorar & 0 & 1 & 2 & 3 & 4 & 5 & 6 \\
\hline 3-) A atividade física pode afetar minhas costas & 0 & 1 & 2 & 3 & 4 & 5 & 6 \\
\hline $\begin{array}{l}\text { 4-) Eu não deveria realizar atividades físicas que } \\
\text { poderiam fazer a minha dor piorar }\end{array}$ & 0 & 1 & 2 & 3 & 4 & 5 & 6 \\
\hline $\begin{array}{l}\text { 5-) Eu não posso realizar atividades físicas que } \\
\text { poderiam fazer a minha dor piorar }\end{array}$ & 0 & 1 & 2 & 3 & 4 & 5 & 6 \\
\hline
\end{tabular}

Para cada afirmação, circular um número de 0 a 6 , para informar quanto o seu trabalho normal afeta ou afetaria sua dor nas costas

\begin{tabular}{|c|c|c|c|c|c|c|c|}
\hline $\begin{array}{l}\text { 6-) Minha dor foi causada pelo meu trabalho ou por } \\
\text { um acidente de trabalho }\end{array}$ & 0 & 1 & 2 & 3 & 4 & 5 & 6 \\
\hline 7-) Meu trabalho agravou minha dor & 0 & 1 & 2 & 3 & 4 & 5 & 6 \\
\hline $\begin{array}{l}\text { 8-) Eu tenho uma reivindicação de pensão em } \\
\text { virtude da minha dor }\end{array}$ & 0 & 1 & 2 & 3 & 4 & 5 & 6 \\
\hline 9-) Meu trabalho é muito pesado para mim & 0 & 1 & 2 & 3 & 4 & 5 & 6 \\
\hline $\begin{array}{l}\text { 10-) Meu trabalho faz ou poderia fazer minha dor } \\
\text { piorar }\end{array}$ & 0 & 1 & 2 & 3 & 4 & 5 & 6 \\
\hline 11-) Meu trabalho pode prejudicar minhas costas & 0 & 1 & 2 & 3 & 4 & 5 & 6 \\
\hline $\begin{array}{l}\text { 12-) Eu não deveria realizar meu trabalho normal } \\
\text { com minha dor atual }\end{array}$ & 0 & 1 & 2 & 3 & 4 & 5 & 6 \\
\hline $\begin{array}{l}\text { 13-) Eu não posso realizar meu trabalho normal com } \\
\text { minha dor atual }\end{array}$ & 0 & 1 & 2 & 3 & 4 & 5 & 6 \\
\hline $\begin{array}{l}\text { 14-) Eu não posso realizar meu trabalho normal até } \\
\text { que minha dor seja tratada }\end{array}$ & 0 & 1 & 2 & 3 & 4 & 5 & 6 \\
\hline $\begin{array}{l}\text { 15-) Eu não acho que estarei de volta ao trabalho } \\
\text { normal dentro de três meses }\end{array}$ & 0 & 1 & 2 & 3 & 4 & 5 & 6 \\
\hline $\begin{array}{l}\text { 16-) Eu não acho que algum dia estarei apto para } \\
\text { retornar ao meu trabalho }\end{array}$ & 0 & 1 & 2 & 3 & 4 & 5 & 6 \\
\hline
\end{tabular}

FABQ-Phys: alternativas relacionadas à atividade física (itens: 1, 2,3,4 e 5); FABQ-Work: alternativas relacionadas ao trabalho (itens: 6,7,8,9,10,11,12 e15). Os itens $13,14 \mathrm{e} 16$ foram considerados redundantes e o 1 e 8 apresentaram uma correlação pequena. Desta forma estes itens foram excluídos. 